ص ص ص

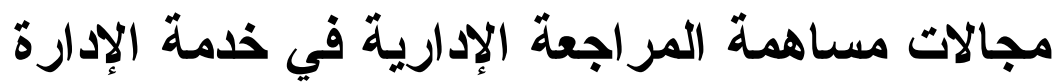

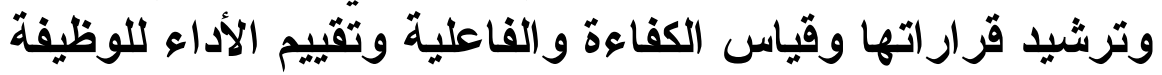

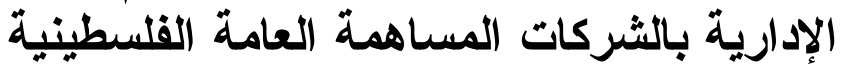

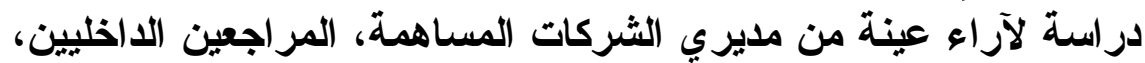

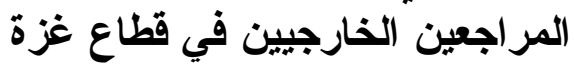

$$
\begin{aligned}
& \text { الدكتور علي سليمان النعامي } \\
& \text { استاذ الخاسبة والمر اجعة المساعد } \\
& \text { كلية الاقتصاد و العلوم الادارية } \\
& \text { جامعة الازهر -فلسطين }
\end{aligned}
$$

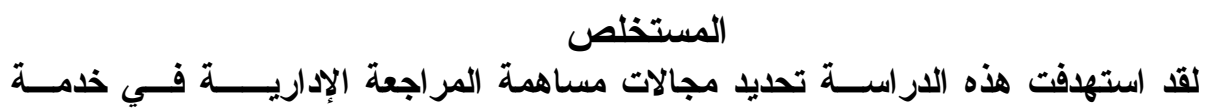

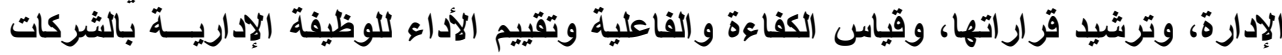

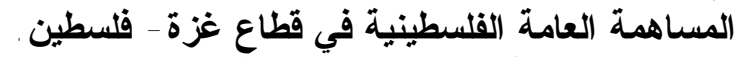

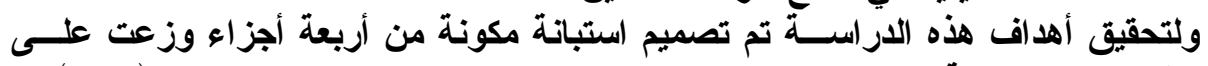

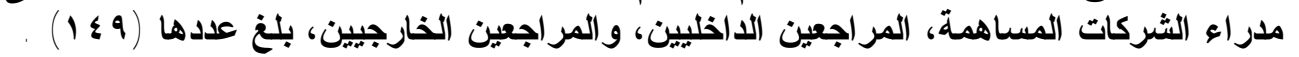

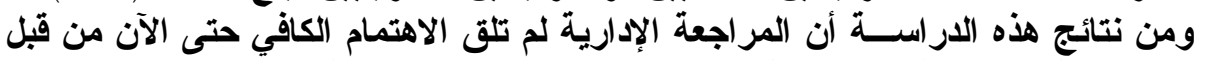

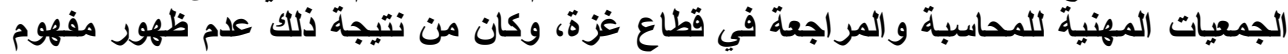

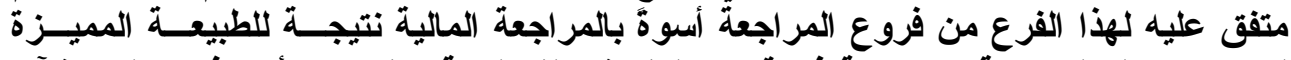

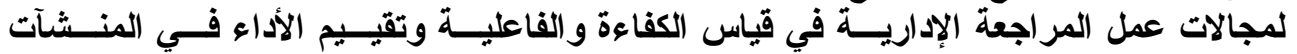

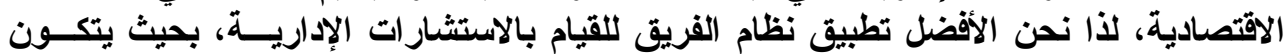

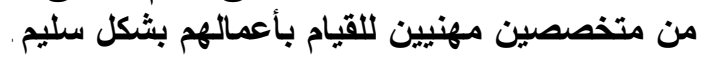

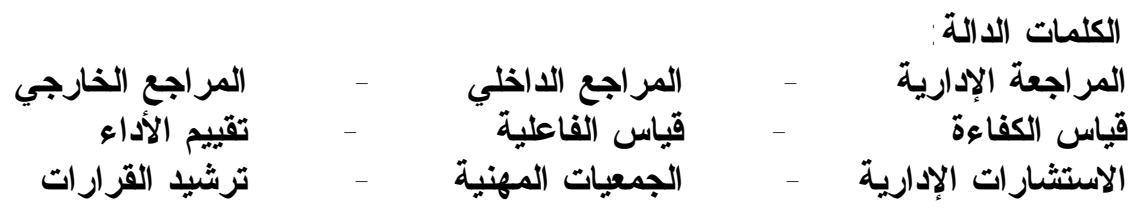

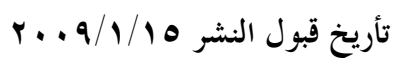

$$
\begin{aligned}
& \text { تأريخ استلام البحث بr/ • / . . . ץ }
\end{aligned}
$$


الدكتور النعامي

\title{
The Spaces of Managerial Auditing in Serving the Administration, Rationalizing Decisions, Measuring the Performance and Efficiency, and Evaluating the Administrative Performance in Palestinian General Companies: \\ A Pilot Study to Managers' Opinions of Companies, Internal Auditors, External Auditors in Gaza Province
}

\author{
Ali S. Al-Nua'mi (PhD) \\ Assistant Professor of Accounting and Audition \\ Al-Azhar University - Palestine
}

\begin{abstract}
This study aims at identifying the contribution fields of managerial auditing to serve the management. The rationalization of its decisions, measuring the efficiency, effectiveness and evaluating the performance of the managerial job at the Palestinian General Corporations in Gaza Province, Palestine. To achieve these objectives, a questionnaire has been developed, depending on previous studies and theoretical studies Consisted from four parts, distributed to the Managers of Corporations, internal auditors and external auditors. The questionnaires were (149). The results of this study showing that the managerial auditing did not achieve a sufficient importance from accounting and auditing professional associations in Gaza Province, as a result there is unacceptable concept such as the financial auditing. Because of the distinctive nature of the managerial auditing work in measuring the efficiency, effectiveness and evaluating the performance of the economic establishments, it is preferable to utilize the "team System" in providing consulting services. The two researchers introduced a set of recommendations, the most important from them: the necessity to find out an integrated system for auditing the activities of the projects, through the financial auditing, the Income Statement and the Balance Sheet can be verified. Through the managerial auditing the measuring of efficiency, effectiveness and evaluating the performance can be achieved. The Professional Associations of Accounting and Auditing in Gaza Province must develop the instructions and standards related to the measurement of efficiency, effectiveness and the evaluating of performance for the economic projects. Keywords: Managerial Auditing - Internal Auditor - External Auditor - Measuring Efficiency - Measuring Effectiveness - Evaluating the Performance - Managerial Consulting - Professional Associations - Rationalization of Decisions.
\end{abstract}

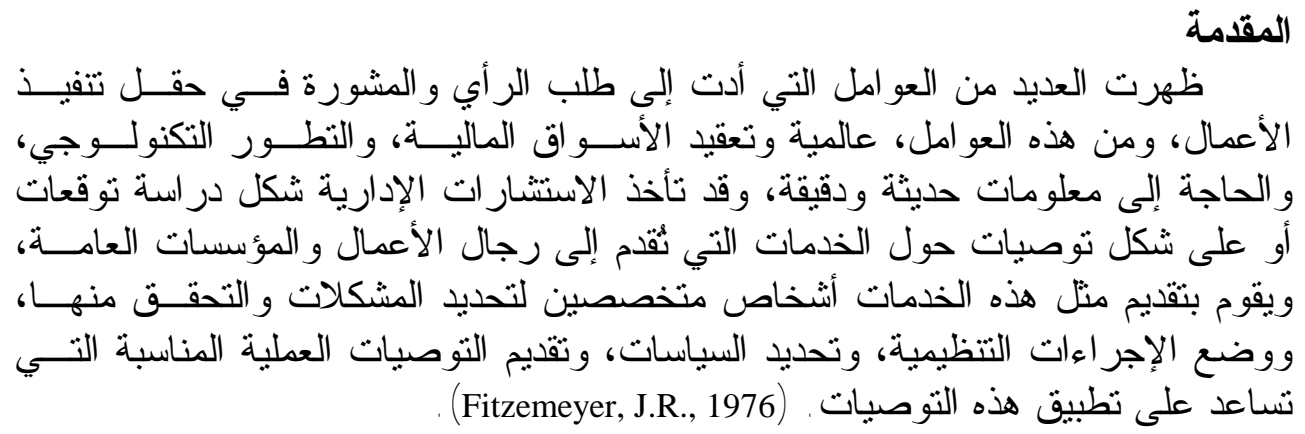


كما أنه بسبب كبر حجم المشروعات، وتعدد أوجــه نـشـاطها، أن أصــبحت إدارة

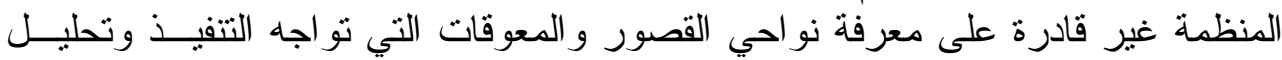

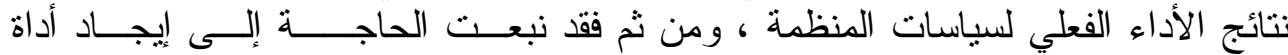

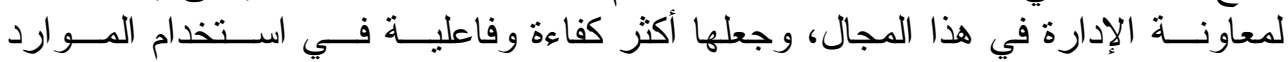

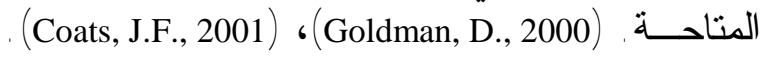
ولقد أسهمت الجمعيات المهنية للمحاسبة والمر اجعة في تطوير دور المر اجعة مــن

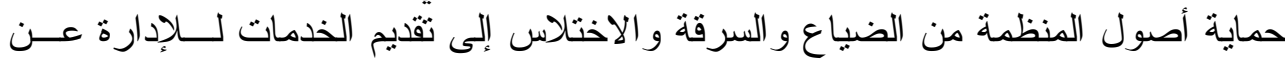

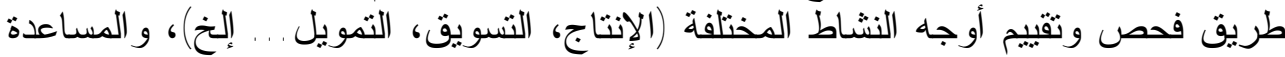

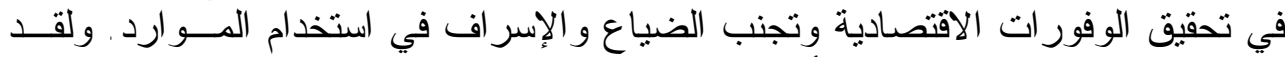

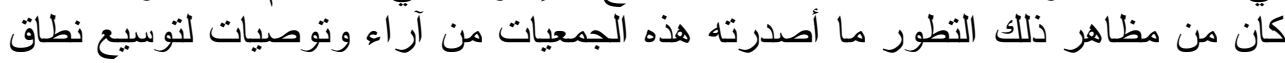

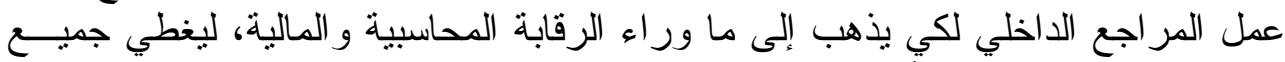

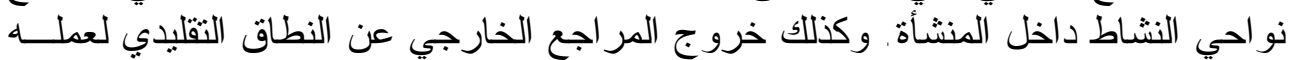

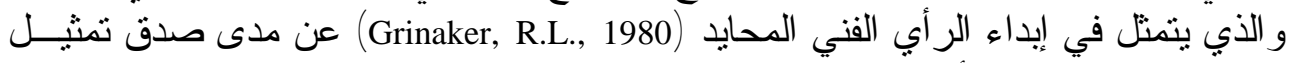

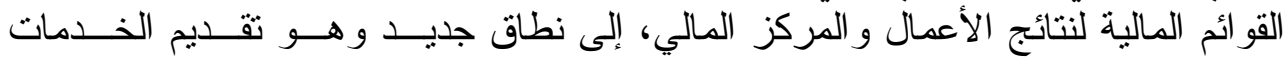

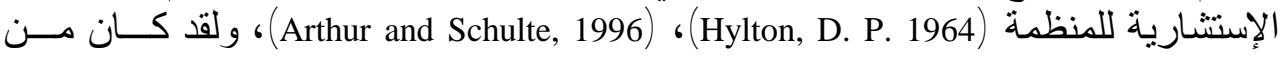

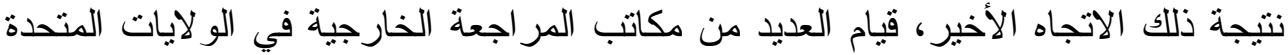

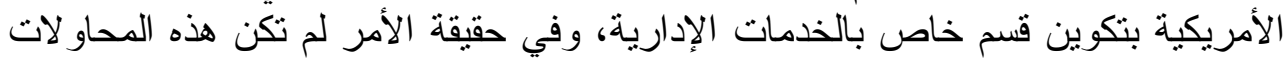

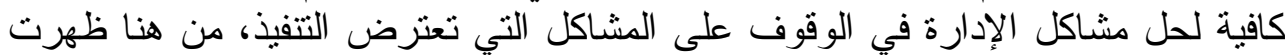

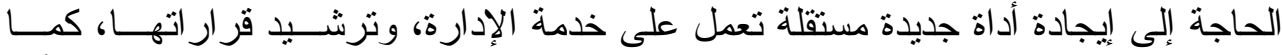

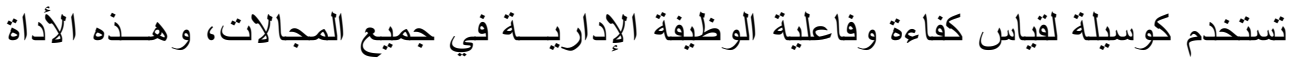

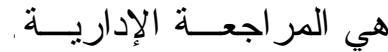

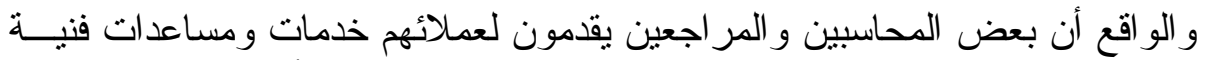

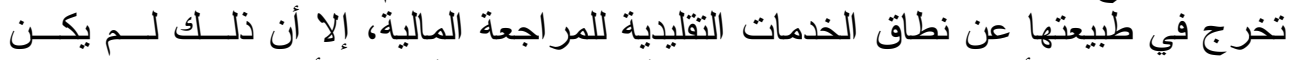

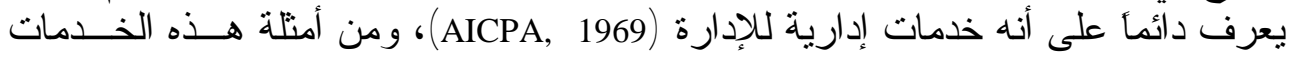

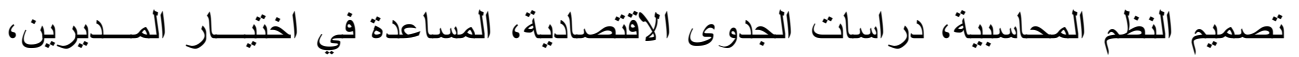

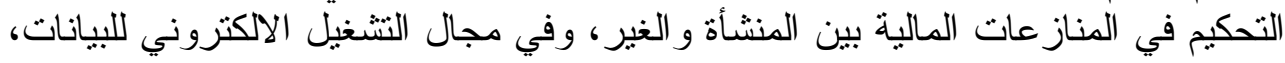

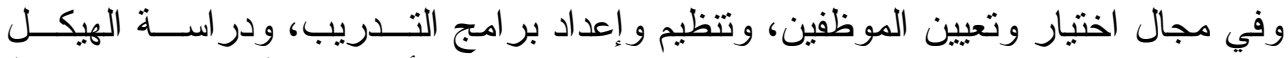

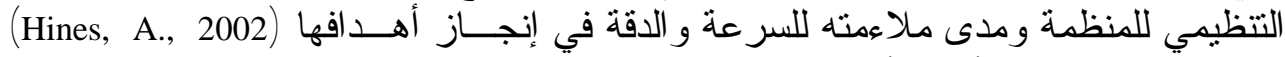

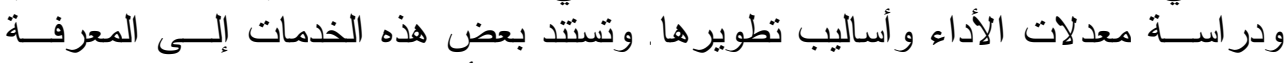

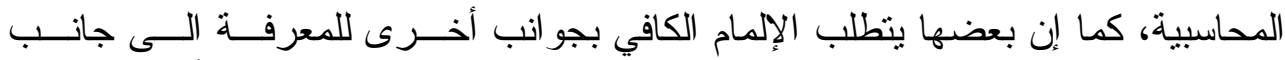

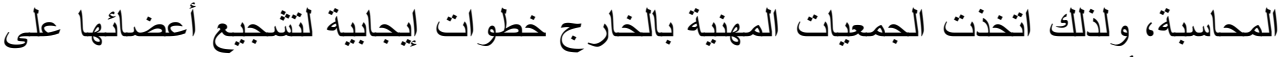

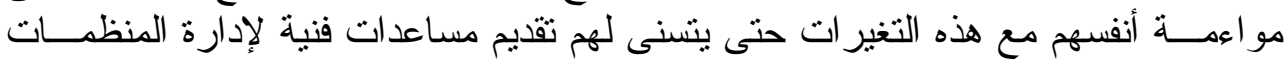

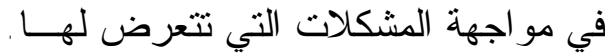

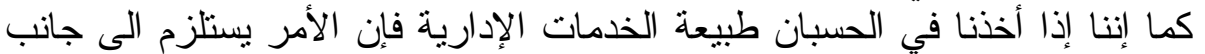

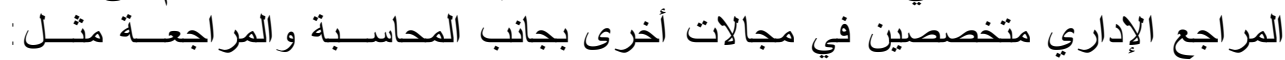

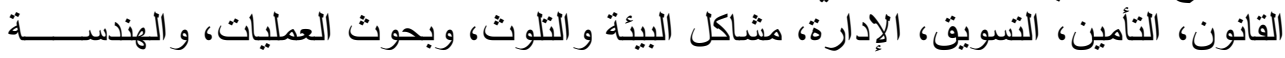

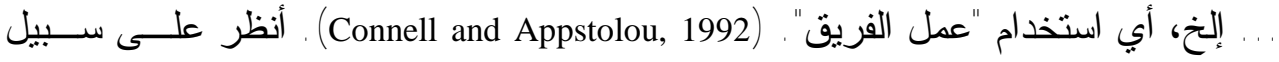




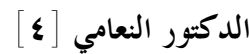

.(Voros, 2001) . (Newell, “et.al.”, 1992) . (Slaughter, 1999)

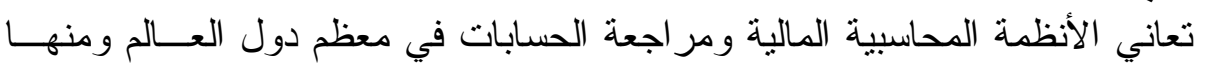

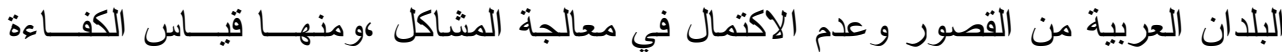

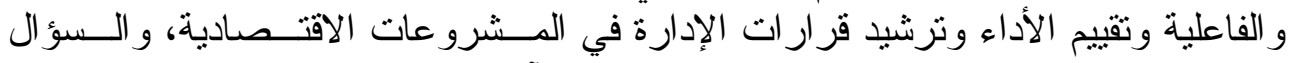

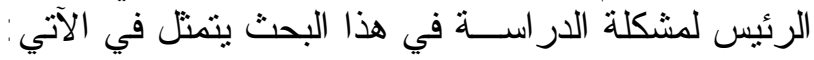

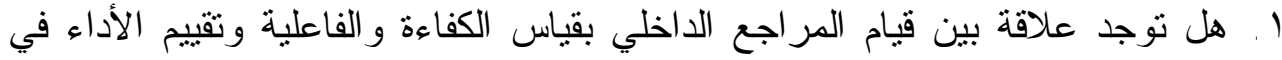
المشروعات الاقتصادية وبين مساهمة المراجعة الإلدارية في في خدمة الإدارة وترشيد

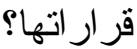
r ـ هل توجد علاقــة بين قيام المر اجع الخارجي بقياس الكفاءة و الفاعلية وتقيبيم الأداء في الإدي المشروعات الاقتصادية وبين مساهمة المر اجعة الإدارية في خدمة الإدارة وترشيد قر ار اتها.

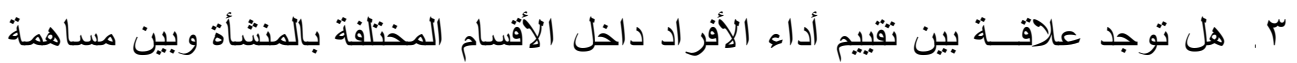

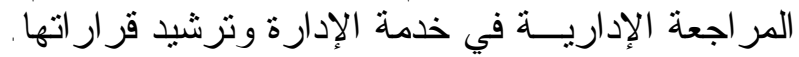

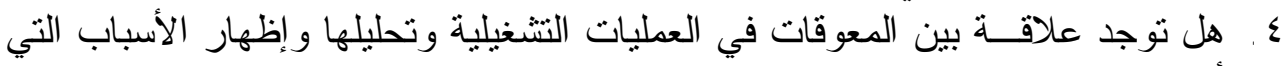

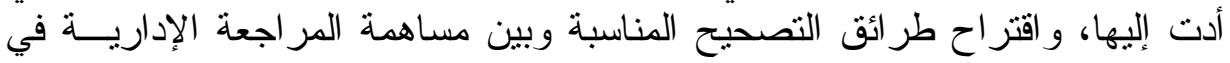
خدمة الإدارة وترشيد قر ار اتها الفر الفي

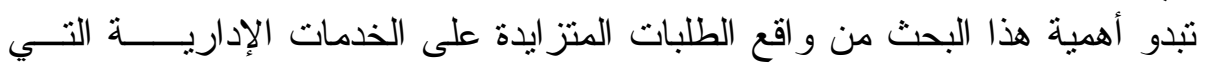
أهمية البحث

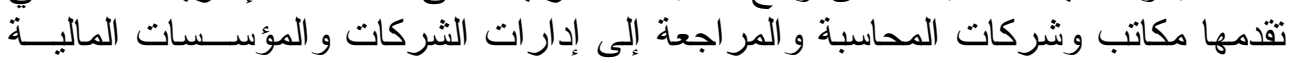

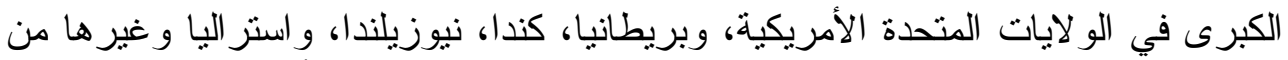

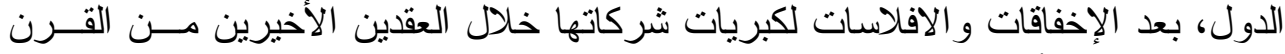

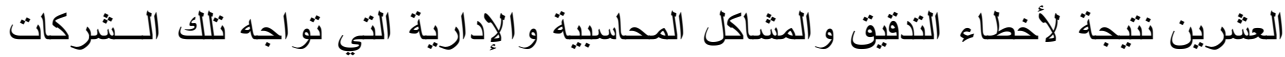

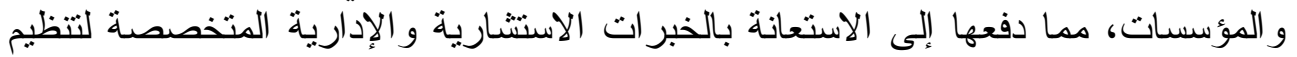

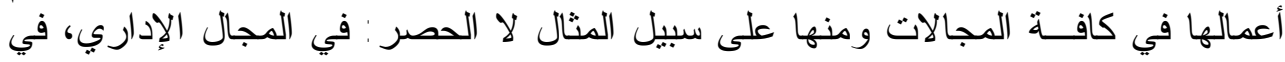

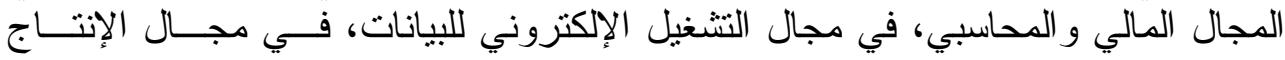

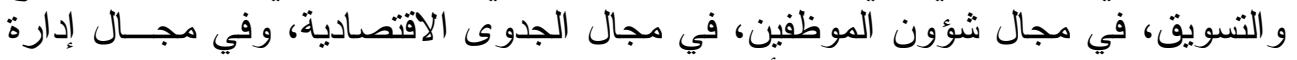

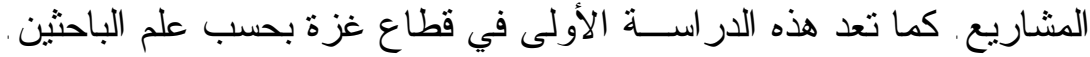

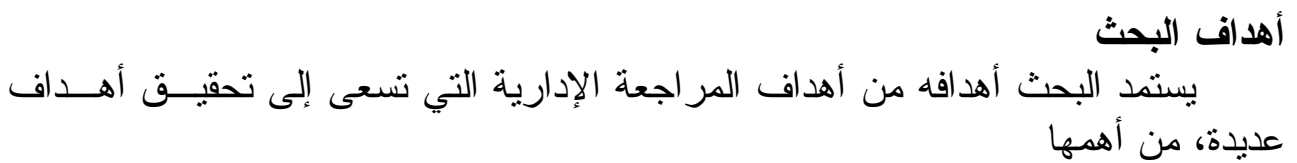
ا ـ إيداء الر أي فيما إذا كانت الإدارة قد استخدمت الموارد المتاحسـة البـشرية و الماديـــة

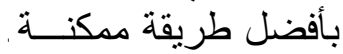




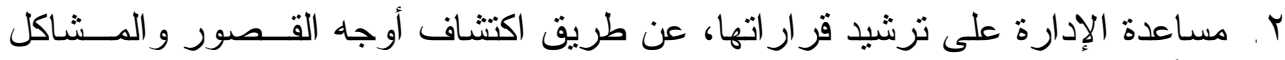

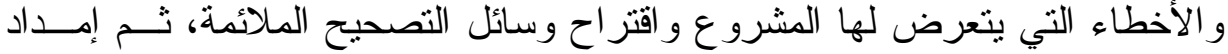

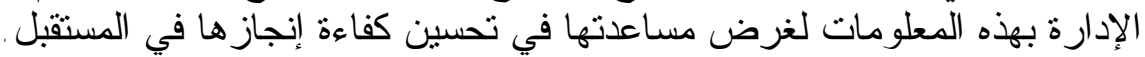

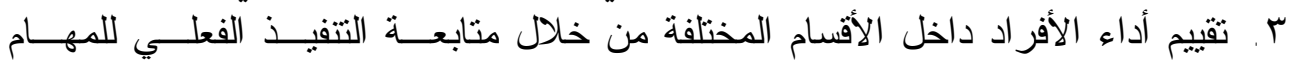

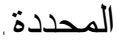

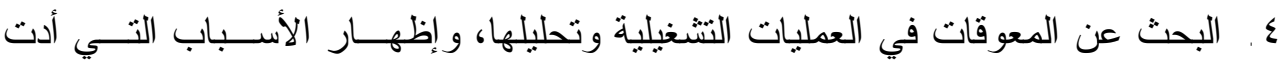

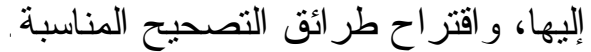

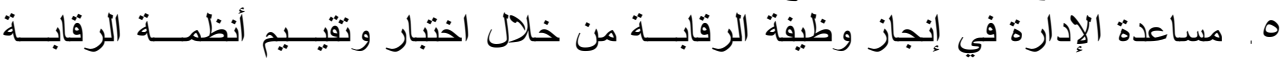

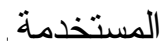

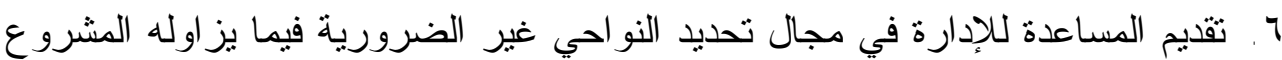

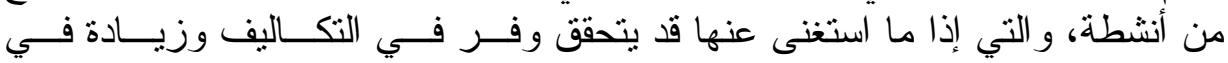

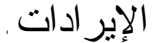

لقد اعتمد الباحثان في الإجابة على مشكلة البحث و أهدافه على الفرضيات الآتية: القرضية الأولى اعتى "لا توجد علاقة ذات دلالة إحصائية بين قيام المر اجع الداخلي بقياس الكفاءة و الفاعلية

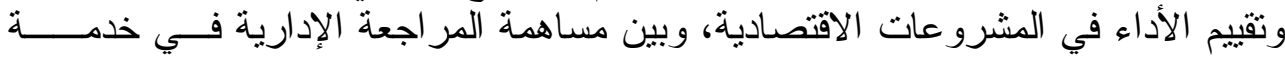

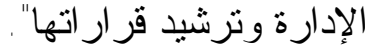

الفرضية الثانية

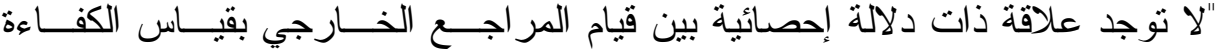

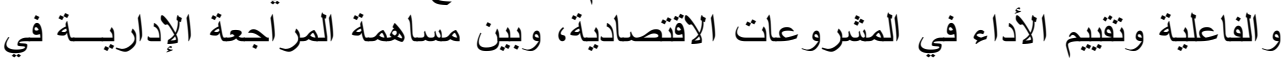

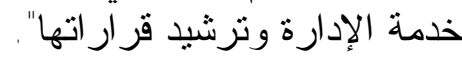

\section{الفرضية الثالثة}

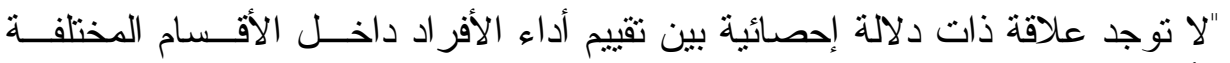

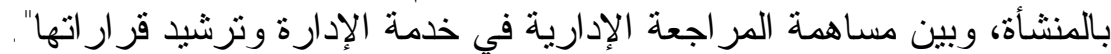

الفرضية الر (بعة

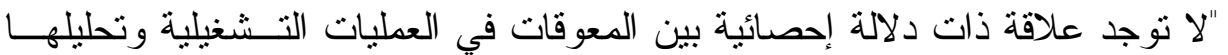

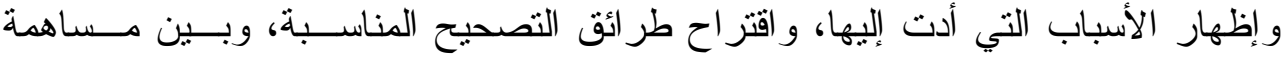

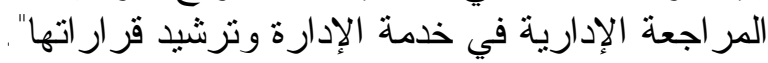

الارسات السابقة: أ. الدر اسة العربية السية: 1. دراسة (فاعوري، (99 19) بعنوان: "حول تقديم خدمات متكاملة للعميل"، حيث بينت الدراســة أن أعمال الاستشار ات الإدارية قد تطورت من مجرد كونها عمل ثانوي 
الدكتور النعامي [־]

يدور في فلك المحاسبة و المر اجعة إلى وجه منفرد مستقل يقدم العديد من الخدمات

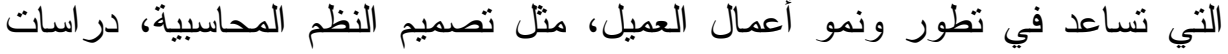

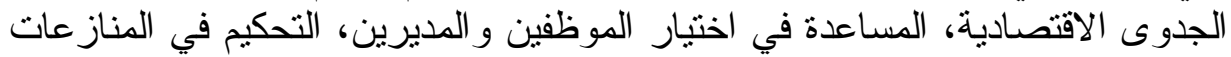

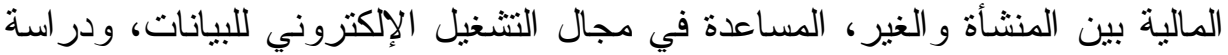

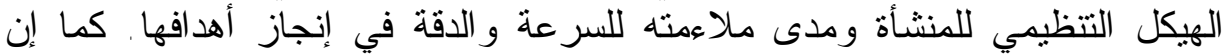

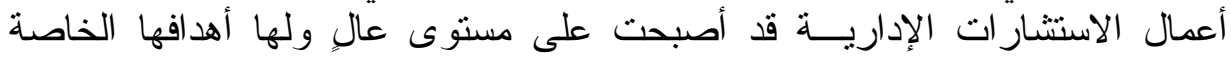

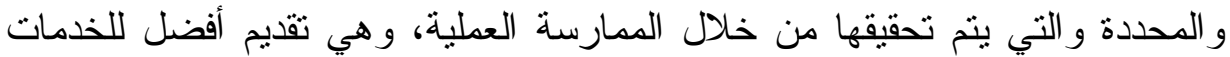
الإداريــة باستقلالية وموضوعية في العمل مع المسؤولية الكاملة عن الأعمال المنفذة.

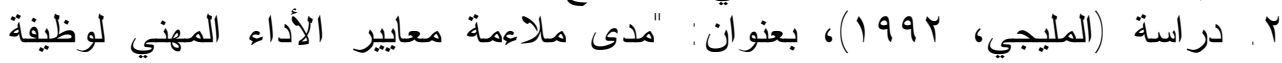

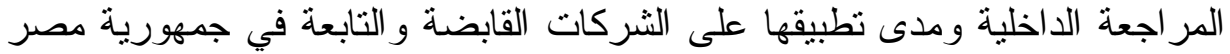

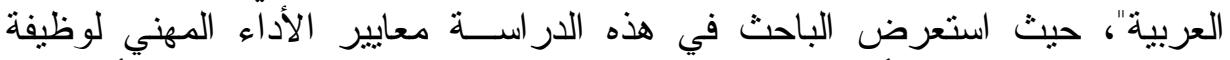

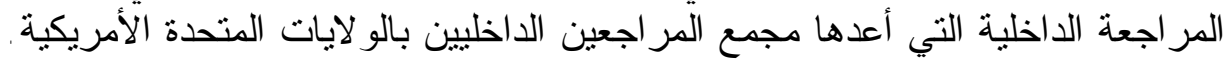

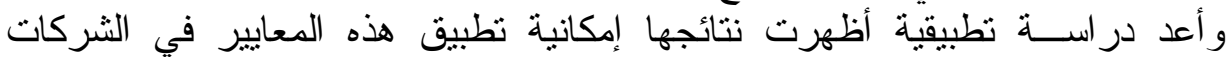

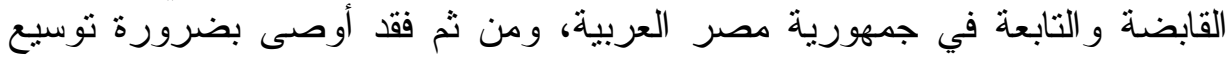

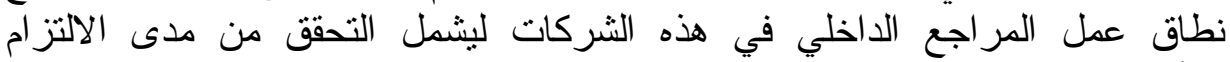

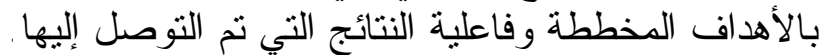

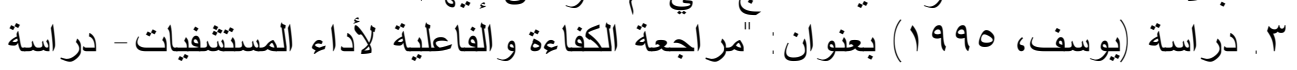

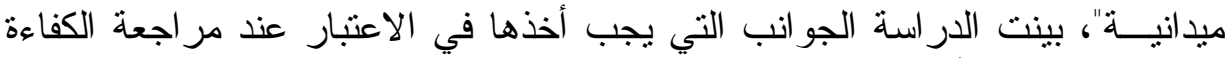

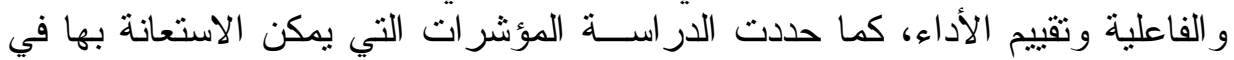

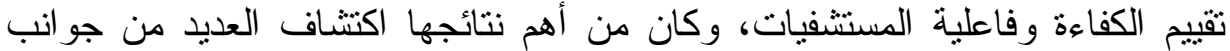

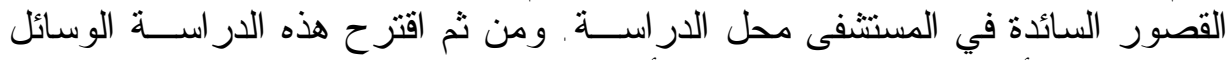

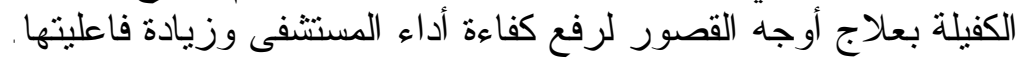

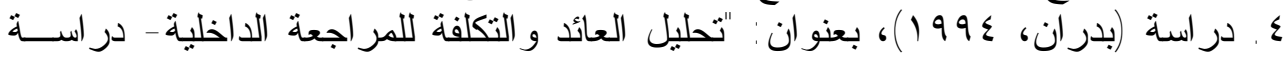

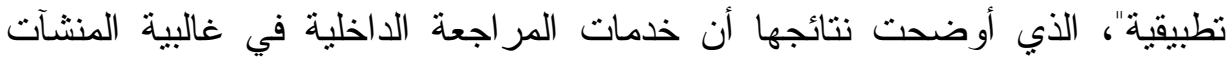

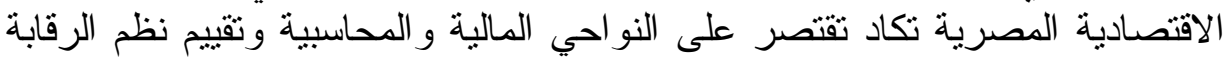
الأللية. وقد بينت الدراســة أن السبب في ذللك هو تبعية قسم المراجعة الداخلية

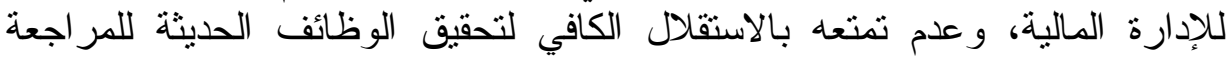

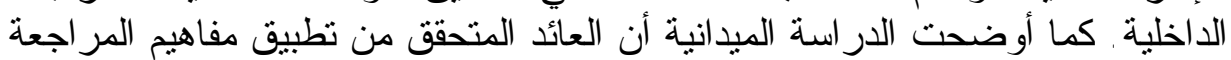

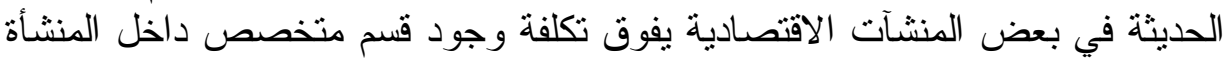
للقيام بها.

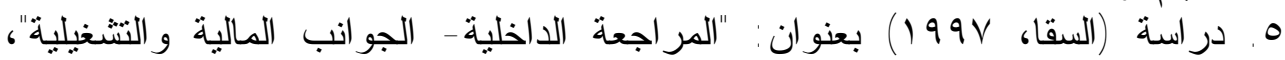

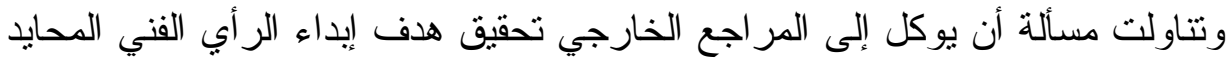

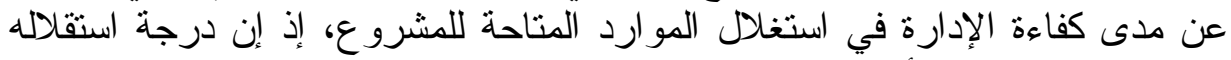

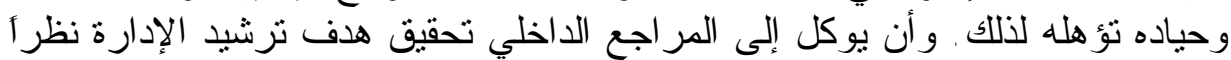

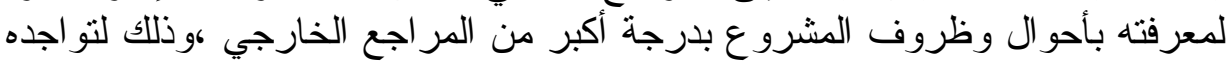

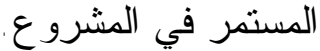

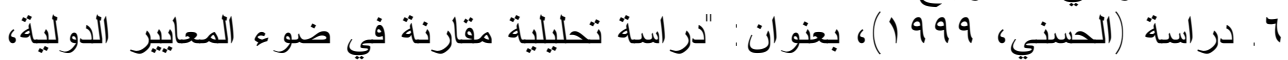

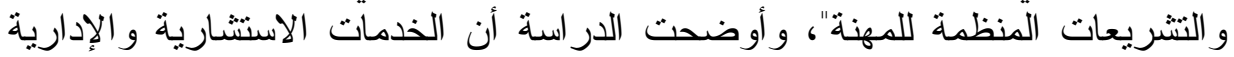

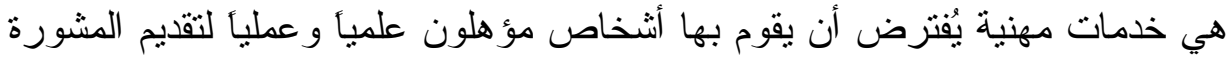


و المساعدة على أساس مهني، وذللك عن طريق تحديد المشاكل و اقتر اح الحلول

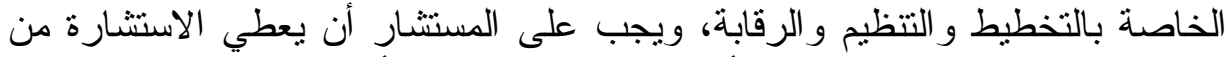

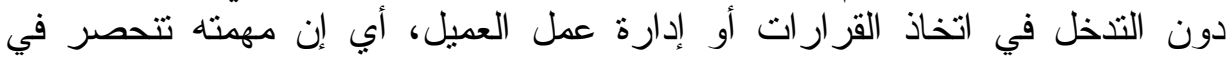

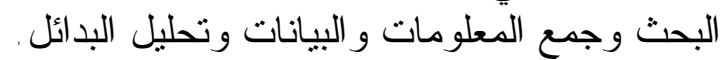

ب. ب. الدراسات الأجنبية

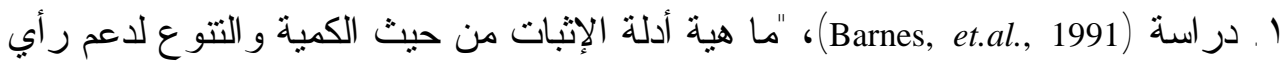

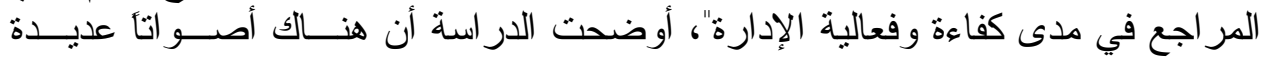

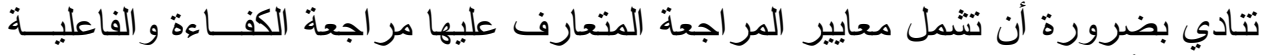

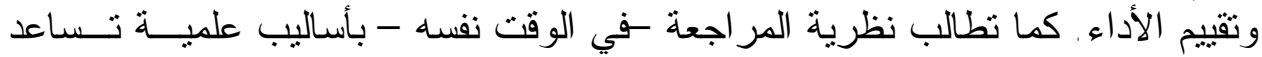

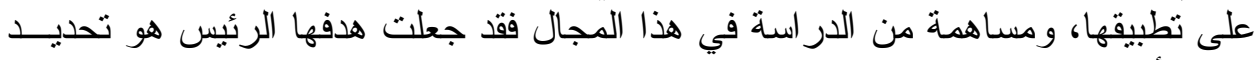

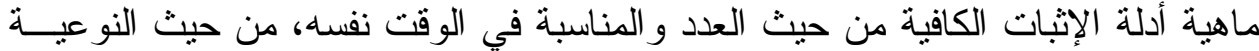

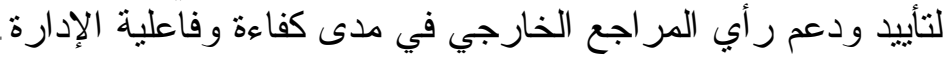

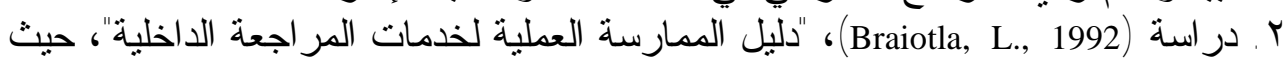

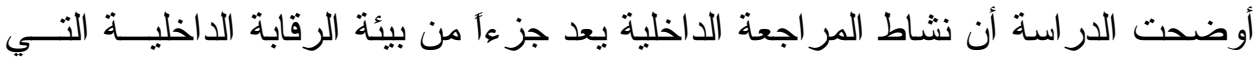

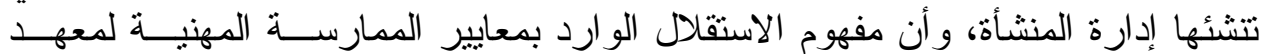

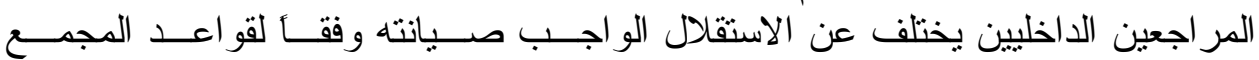

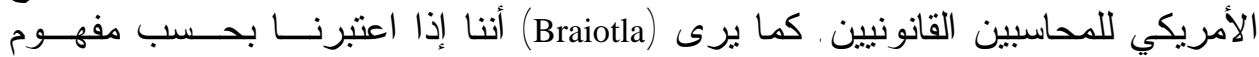

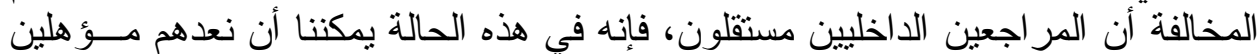
للقيام بعملية مر اجعة القو ائم الماليـــــــة.

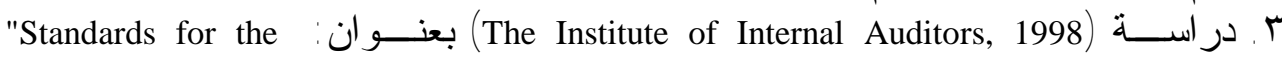
Professional Practice of Internal Auditing"

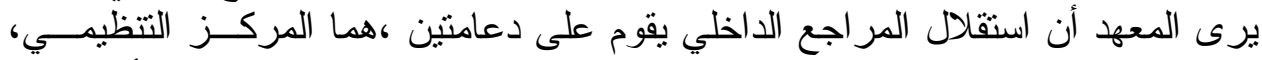

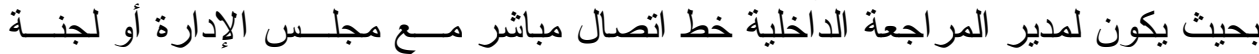

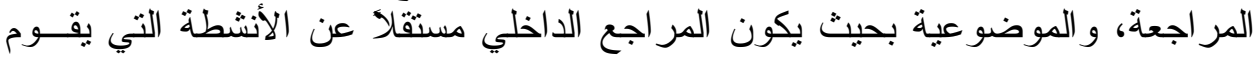

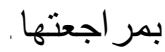

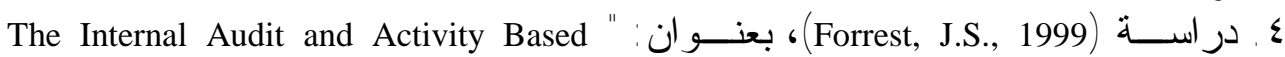
Management

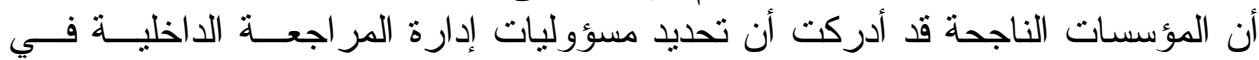

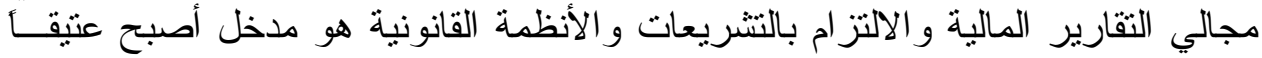

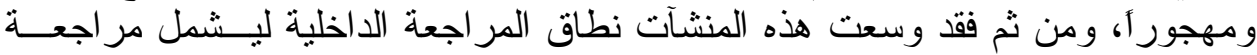

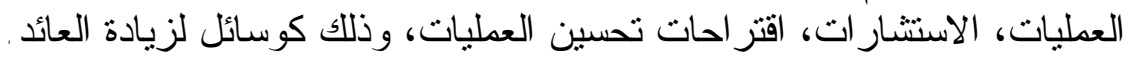

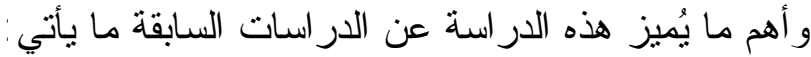

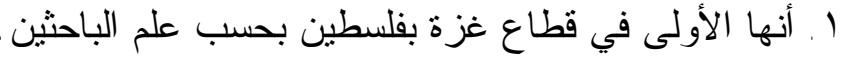

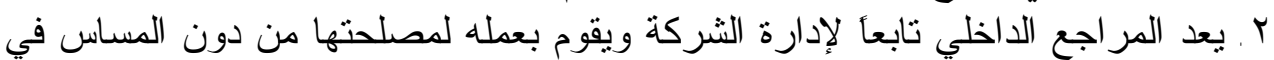

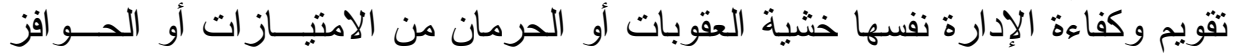




\section{الدكتور النعامي [N]]}

r. يتم ترشيح الأشخاص المناط اليهم القيام بالمر اجعة الداخلية من قبل الإدارة ذاتها التي الإداء

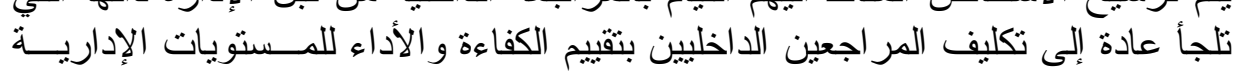

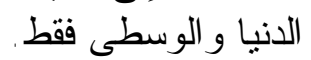

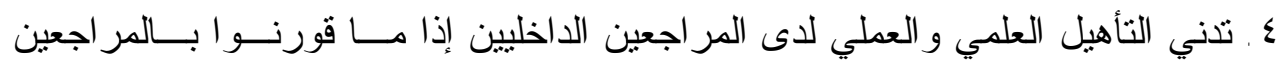
الخار جيين . أنيل

ه. عدم كفاية استقلال المر اجعين الداخليين بسبب تبعينهم لإدارة المشروع، إذا ما قورنوا بالمر اجعين الخارجيين الذين يتمتعون بالحياد و الاستقلال التابن لإدام في أعمالهم .

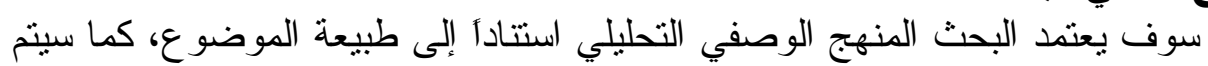
المنهج العلمي للبحث

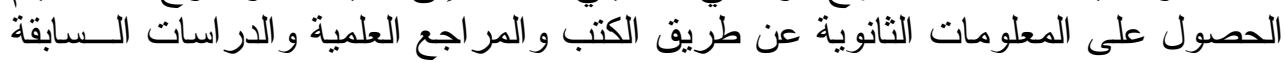

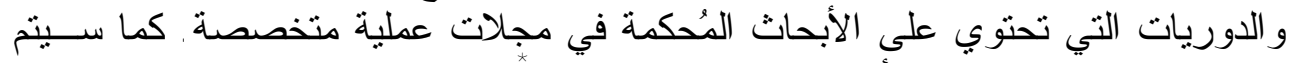

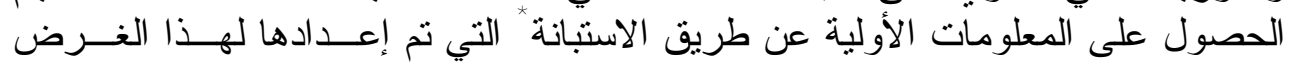
(Questionnaire)

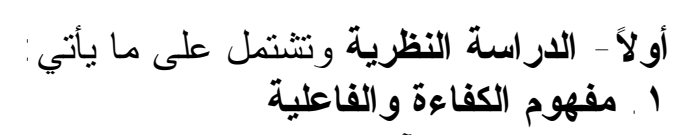

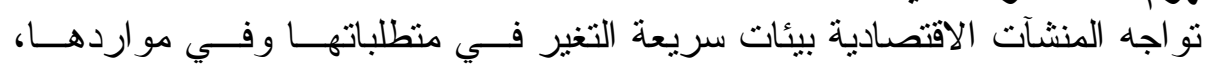

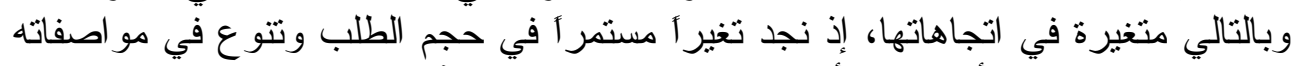

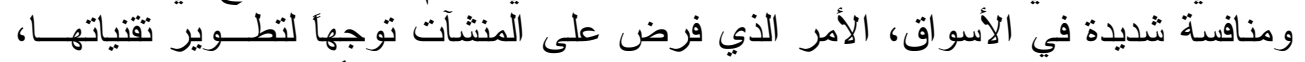

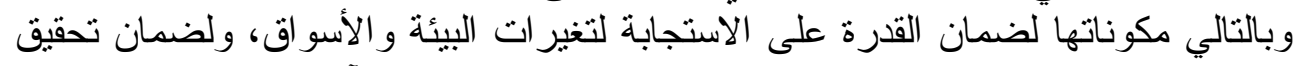

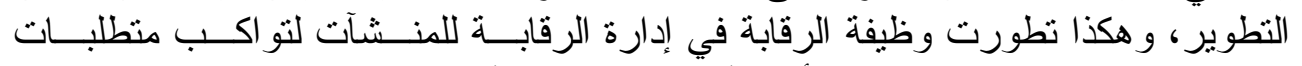

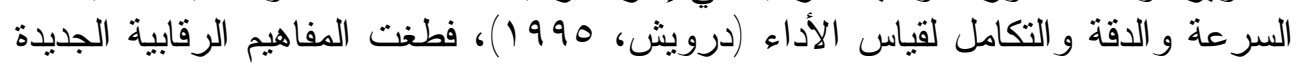

$$
\text { • • • الإدارة الجابلأهداف و والنتائج. }
$$

ولتفعيل هذه المفاهيم الجديدة في إدارة الدهاة المنشآت تم نطوير عدد من المقاييس المتقدمة مثل:

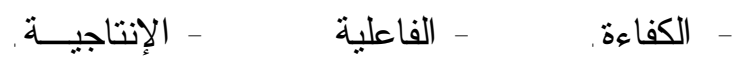

$$
\begin{aligned}
& \text { وذلك تكاملا مع المقاييس التقليدية مثل : }
\end{aligned}
$$

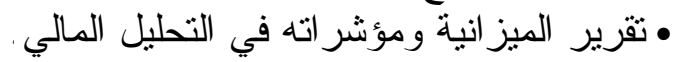

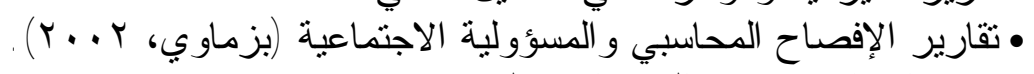

$$
\begin{aligned}
& \text { • مؤشر ات الإسهام في الناتج الإجمالي. }
\end{aligned}
$$

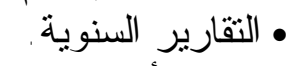

$$
\begin{aligned}
& \text { • تقارير أداء العاملين . (العبادي، } 997 \text { ( ). }
\end{aligned}
$$

(1) ملحق * 


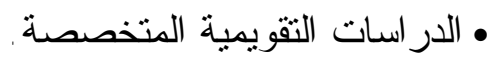

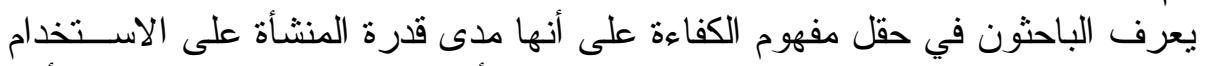

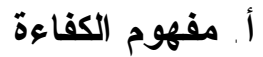

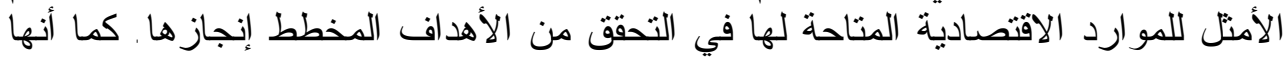

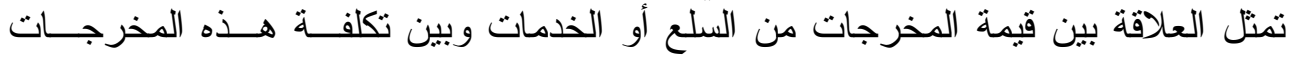

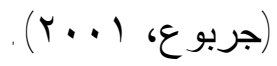

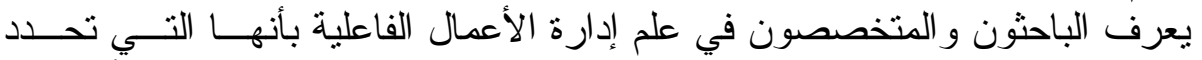

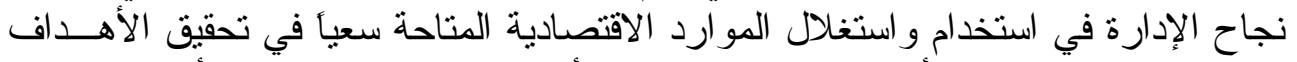

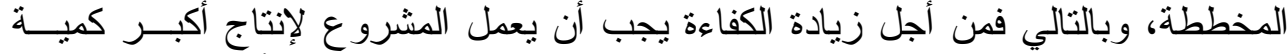

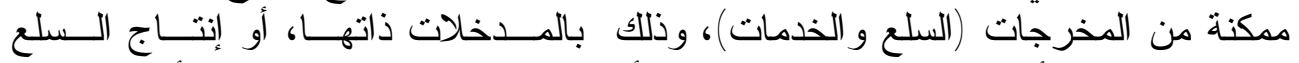

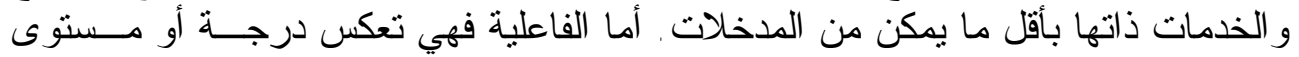

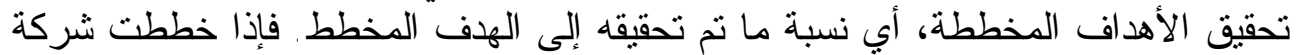

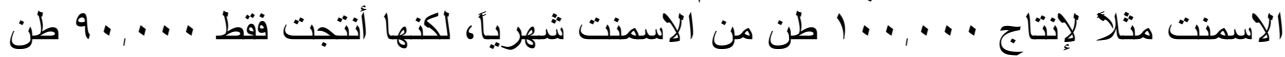

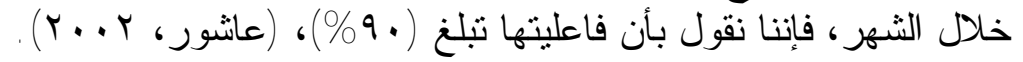

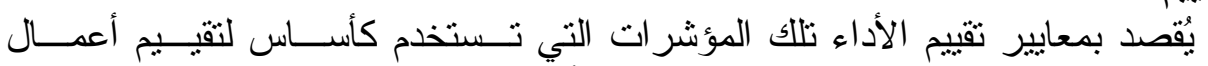

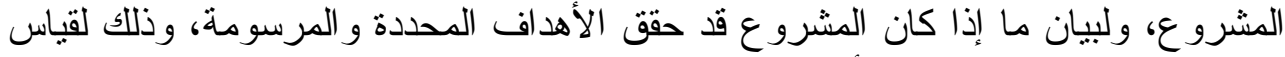

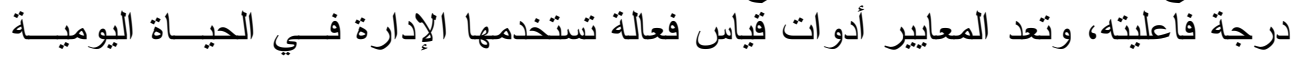

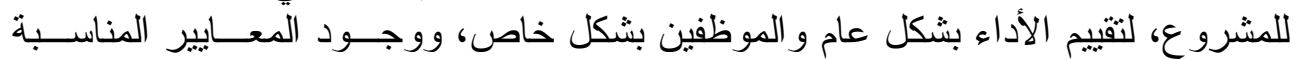

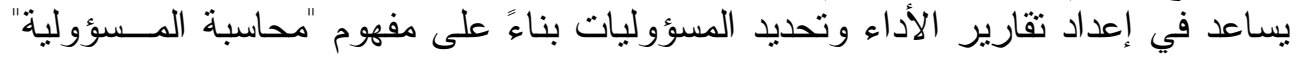

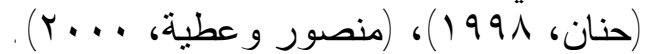

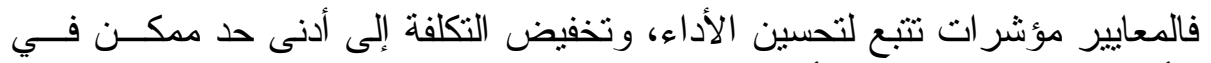

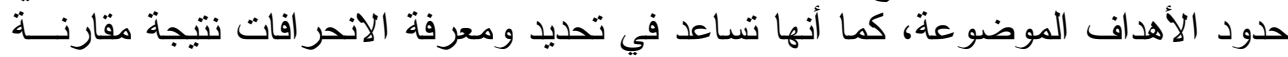

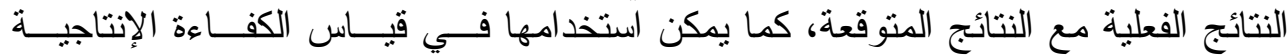

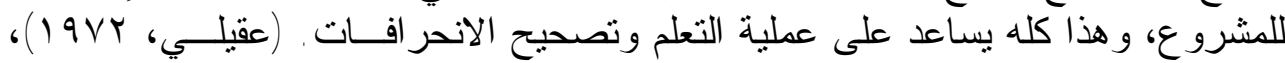

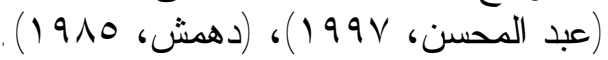

\section{r. قـيام المراجع الداخلي بتقييم الأداء}

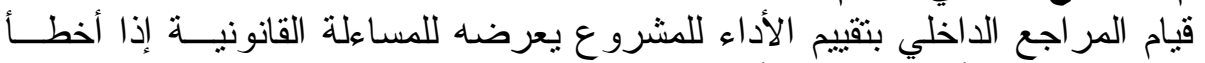

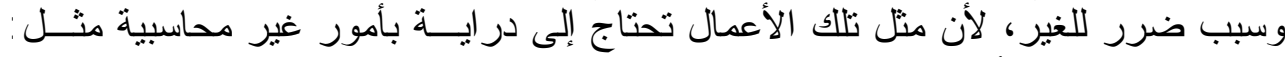

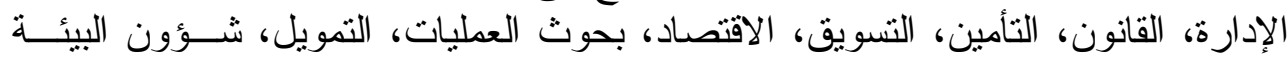

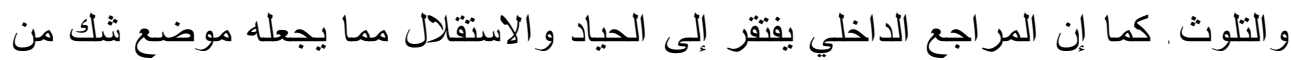
قبل المجتمع المالي للقيام بهذه المهمة (Rittenberg, 1977). 


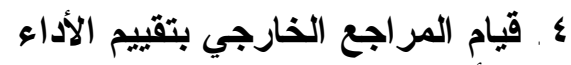

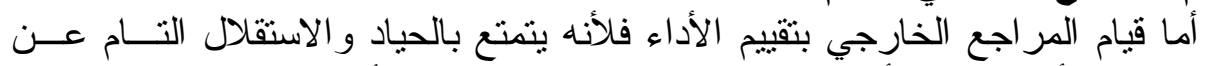

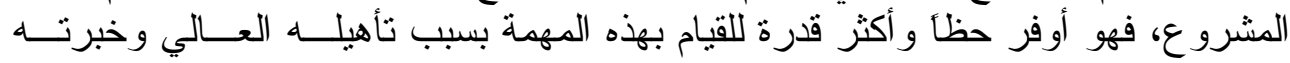

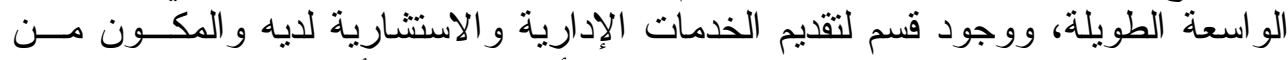

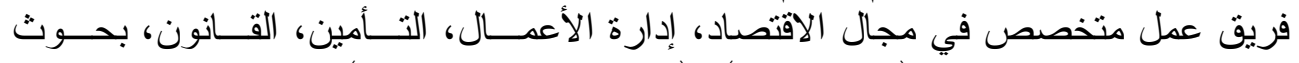
العمليات، التمويل، و البيئة (Antle, 1987)، (Humphrey, et.al., 1992).

للبحث بعد ميداني تطبيقي يتعلق بالوقوف الإنة على مجالات مساهمة المر اجعة الإدارية

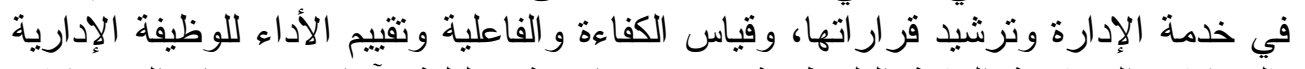

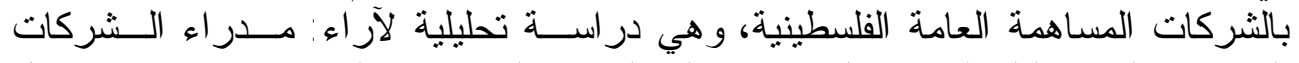

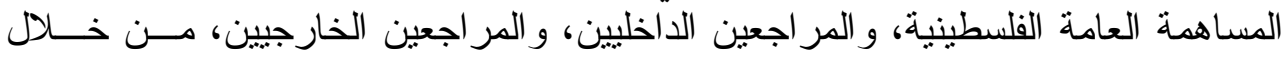

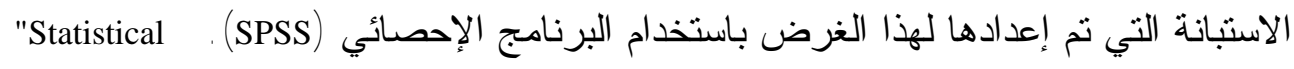
.Program for Social Sciences"

\begin{tabular}{|c|c|}
\hline & مجتمع البحث وعينة \\
\hline 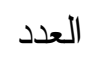 & يتكون مجتمع الدر اسة من الآتي: \\
\hline $7 \varepsilon$ & * مديرو الثركات المساهمة العامة \\
\hline $7 \varepsilon$ & * المر اجعون الداخليـــــون \\
\hline 10 & * المر اجعون الخارجيــون \\
\hline r r & 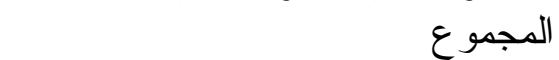 \\
\hline
\end{tabular}

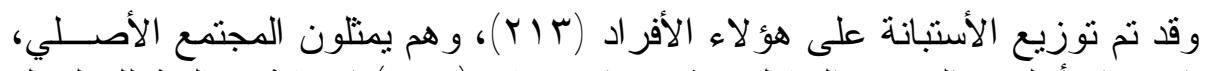

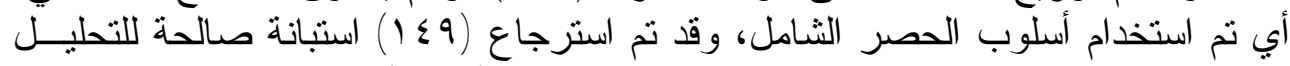

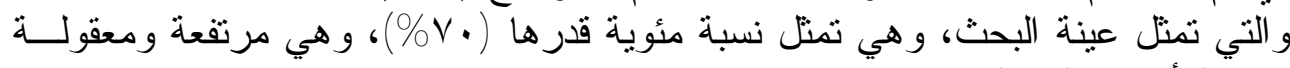
قياساً للأبحاث المماثلة.

\begin{tabular}{|c|c|c|c|c|}
\hline \multicolumn{5}{|c|}{ مفردات مجتمع الدراســة، ومفردات عينة الدراســـة } \\
\hline النسبة المئوية & عينة الاراســة & مجتمع & الإيضاحات & ? \\
\hline$\% r \varepsilon, \varepsilon r$ & Or & $7 \varepsilon$ & مديرو الثركات المساهمة العامة. & 1 \\
\hline$\% r r, \cdots$ & $\sum 9$ & $7 \varepsilon$ & المر اجعون الداخليون. & $r$ \\
\hline$\% r r, O Y$ & $\varepsilon \wedge$ & 10 & المر اجعون الخارجيون . & $r$ \\
\hline$\% \vee \cdot, \cdot \cdot$ & $1 \leqslant 9$ & rIT & المجموع الكلي & \\
\hline
\end{tabular}




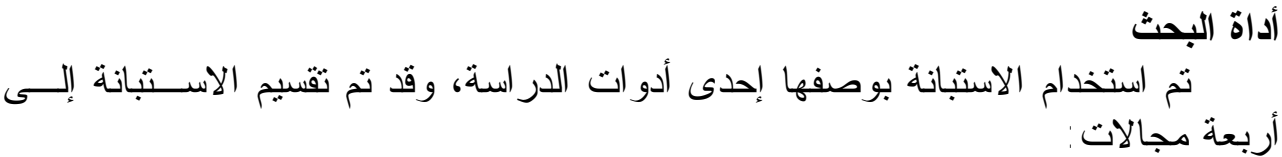

المجال الأول

قيام المر اجع الداخلي بقياس الكفاءة والفاعلية وتقييم الأداء في المنظمة، ويتكون من

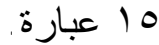

قيام المراليع الخارجي بقياس الكفاءة والفاعلية وتقييم الأداء في المنظمة، ويتكــون

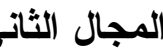
من عال الثبارة.

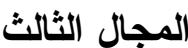

تقييم أداء الأفر اد داخل الأقسام المختلفة بالمنظمة ، ويتكون من 17 عبارة.

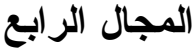

المعوقات في العمليات النشغيلية وتحليلها و إظهار الأسباب التي أدت إليها، و اقتر اح التهات

الطر ائق التي أدت اليها , و اقتر اح طر ائق التصحيح المناسبة، ويتكون من 9 عبار ات التهات

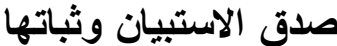

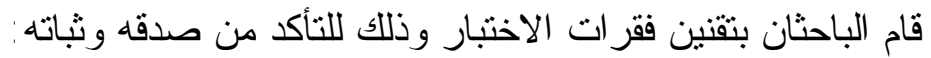
- صدق فقر ات الاستبانة: قام الباحثان بالتأكد من صدق فقر ات الات الاستبانة بطريقتين.

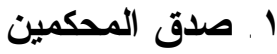

عرض الباحثان الاستبانة على مجموعة من المحكمين تألفت من ( • (1) أعضاء من

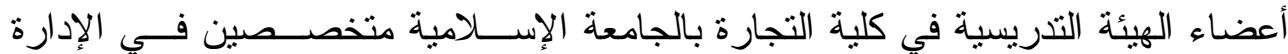

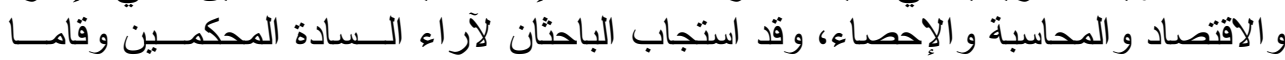

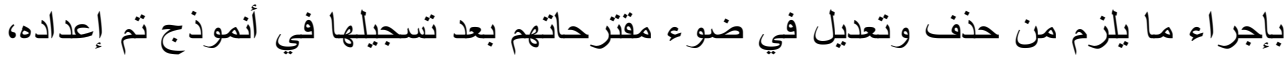

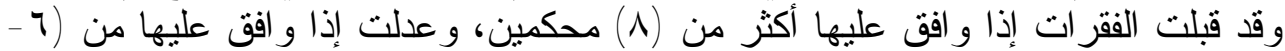

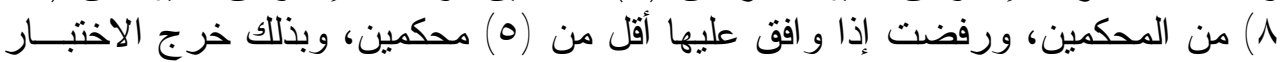
في صورته النهائية ليتم تطبيقه على العينة الاستطلاعية.

Reliability تبات الاستبانة

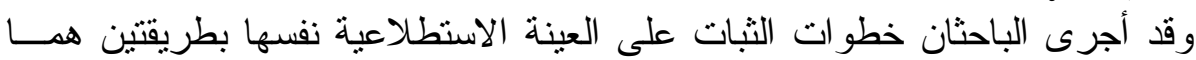
طريقة التجزئة النصفية ومعامل ألفا كرونباخ.

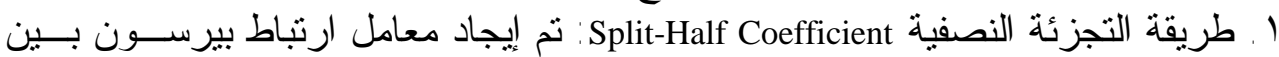

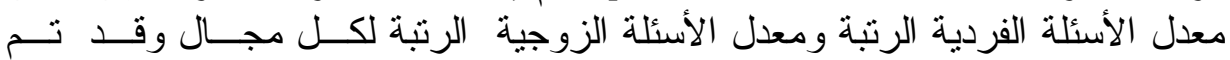

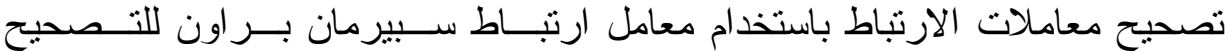
Spearman-Brown Coefficient

معامل الثبات = ثبات كبير نسبيا لفقر ات الاستبيان . 


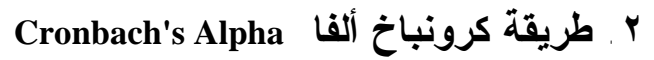

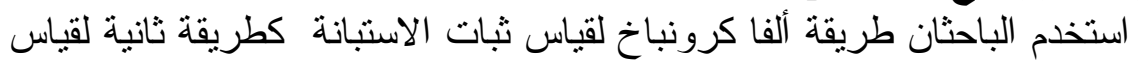
الثبات وقد بين الجدول r أن معاملات الثبات مرتفعة لفقر ات الات الاستبانة .

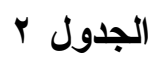

معامل الثبات (طريقة التجزئة النصفية والفا كرونباخ)

\begin{tabular}{|c|c|c|c|c|c|}
\hline \multirow{2}{*}{ طرويقة الفاخ } & \multicolumn{3}{|c|}{ طريقة التجزئة النصفية } & \multirow{2}{*}{ الفقرات } & \multirow[b]{2}{*}{ 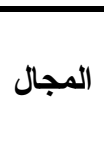 } \\
\hline & المعنوية & معامل الارتباط & الارتباط & & \\
\hline$\cdot$, AYT. & $\because, \cdots$ & $\cdot, 10 \leqslant 707$ & $\cdot, V \leqslant 7 Y$ & 10 & الأول \\
\hline$\cdot, \wedge \mu \mid$. & $\bar{r}, \cdots$ & $\cdot, 9 \ldots \leqslant 90$ & $\cdot, 119$. & $1 \varepsilon$ & الثاني \\
\hline$\cdot, \wedge \cdot 1 \leq$ & $\bar{r}, \cdots$ & $\therefore 9 \cdot 0 \cdot v$ & •, ArTt & 17 & الثالث \\
\hline$\cdot, A Y \cdot Y$ & $\cdot, \cdots$ & $\cdot,(191 \leq 71$ & $\cdot, 70 \leq 9$ & 9 & الرابع \\
\hline
\end{tabular}

المعالجات الإحصائية لقد قام الباحثان بتقريخ وتحليل الاستبانة من خلال برنامج SPSS الإحصائي، وتــم الستخدام الاختبار ات الإحصائية الآتية:

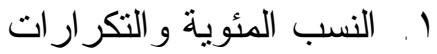

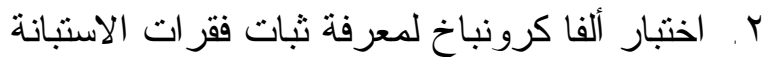

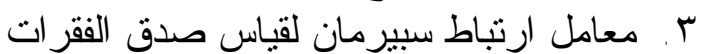
ع. اختبار كولومجروف سمرنوف لمعرفة نوع البيانات، هل تتبع التوزيع الطبيعي أم لا (1-Sample K-S ) O O اختبار One sample T test

اختبار التوزيع الطبيعي (اختبار كولمجروف - سمرنوف (1-Sample K-S)

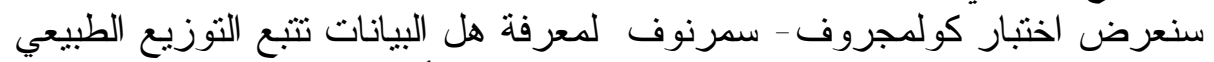

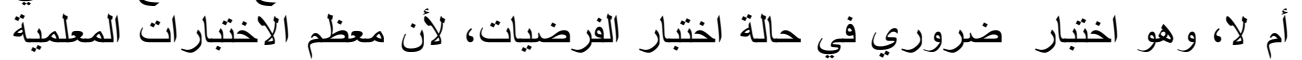

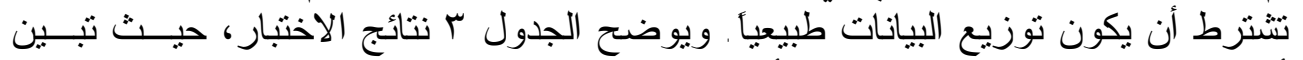

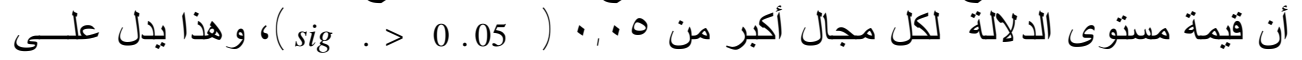
أن البيانات تتبع التوزيع الطبيعي، ويجب الستخدام الاختبار ات المعلمية. 


\begin{tabular}{|c|c|c|}
\hline \multicolumn{3}{|c|}{ الجدول r } \\
\hline مستوى المعنوية & قيمة الاختبار z & المجال \\
\hline$\cdot, r \leqslant$. & $\cdot, 9 \leqslant$. & الأول \\
\hline., 094 & $\cdot, V \vee$. & الثاني \\
\hline$\cdot$, YOY & $1, \cdot 1 \mathrm{~V}$ & الثالث \\
\hline$\cdot, v \cdot 9$ & $\cdot, V \cdot Y$ & الرابع \\
\hline 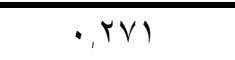 & $\cdot, 999$ & جميع المجالات \\
\hline
\end{tabular}

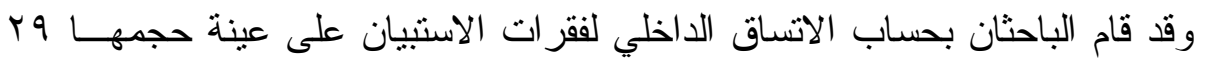

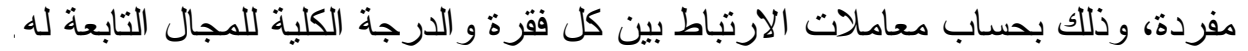

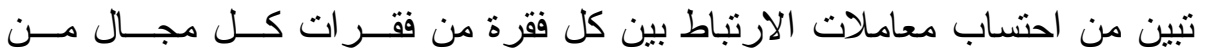

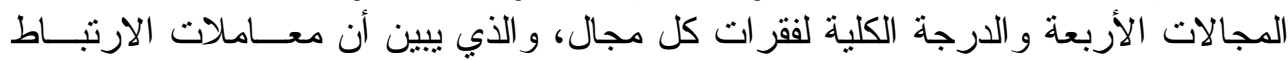

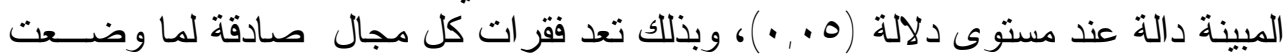
لقياسه .

\section{اختبار فرضيات الاراسة}

تم استخدام اختبار T للعينة الواحدة (One Sample T test) لتحليل فقر ات الاستــتبانة،

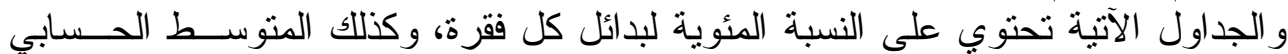
و الوزن النسبي وقيمة t ومستوى الدلالة لكل فقرة ، وتكون الفقرة إيجابية بمعنى أن أفراد الدي

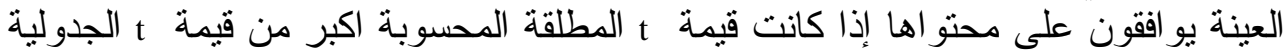

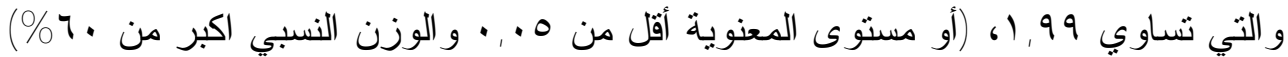

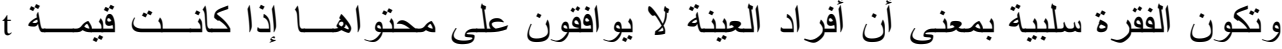

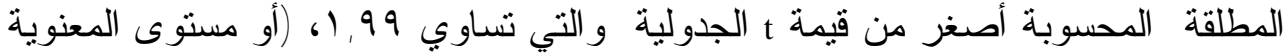

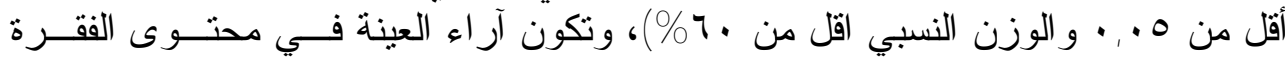
محايدة إذا كانت قيمة مسنوى المعنوية اكبر ه •. • .

"لا توجد علاقة عند مستوى دلالة إحصائية ه •., • بين قيام المر اجع الداخلي بقياس

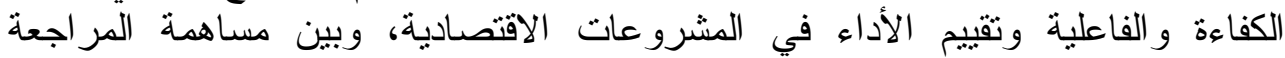

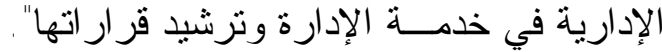

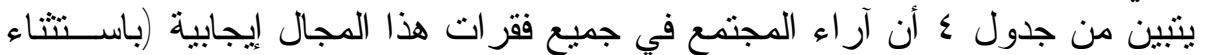

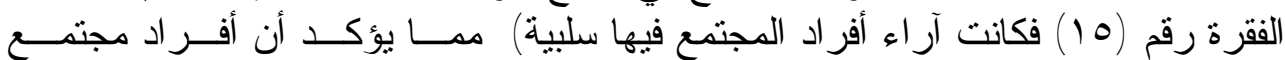

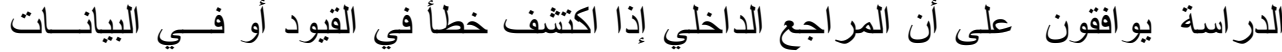

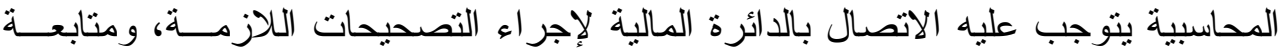

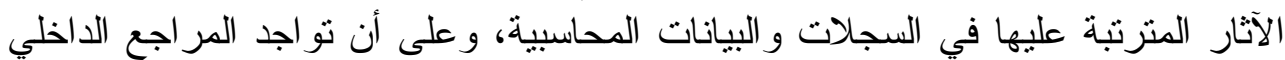

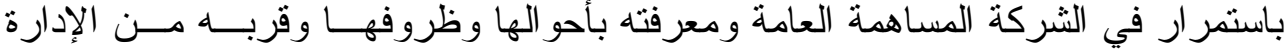




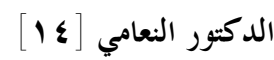

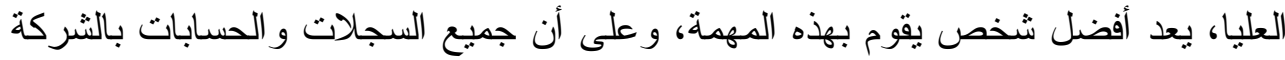

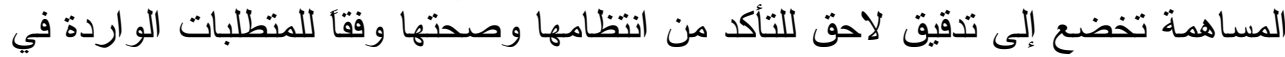

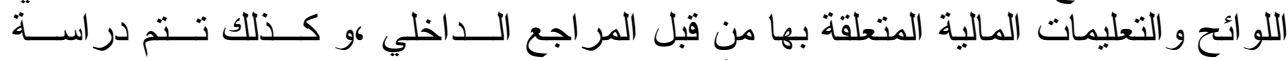

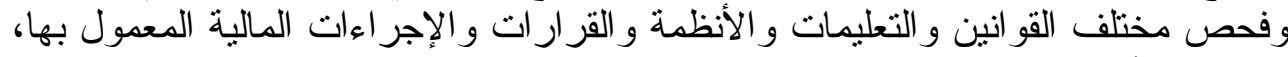

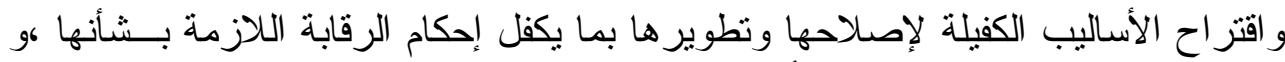

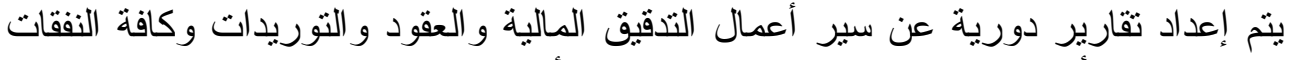

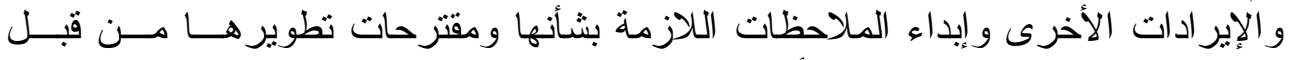

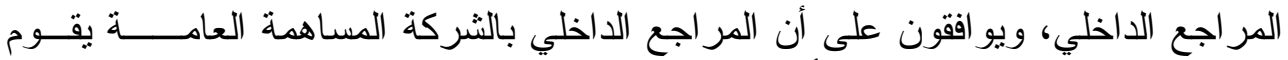

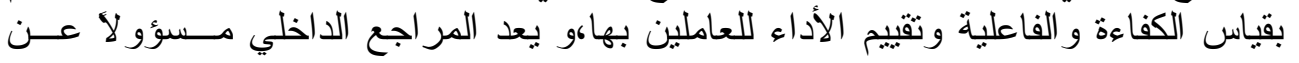

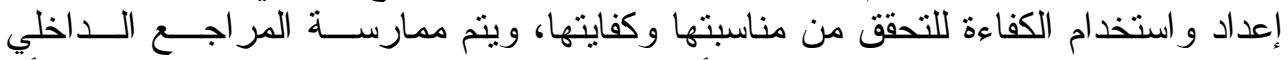

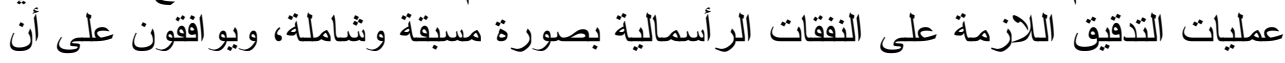

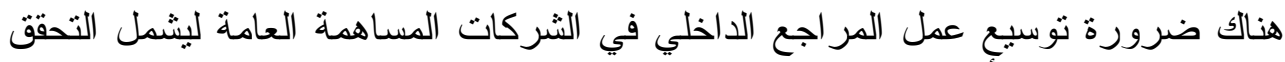

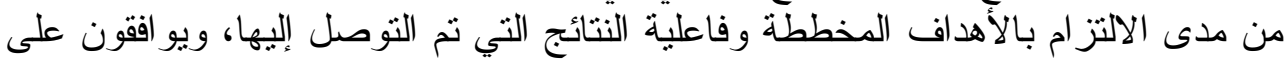

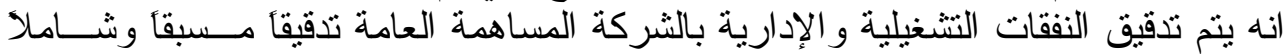

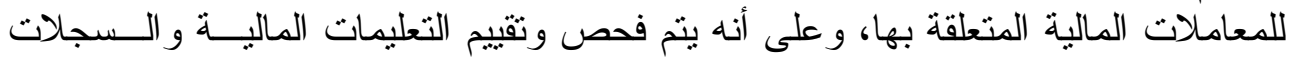

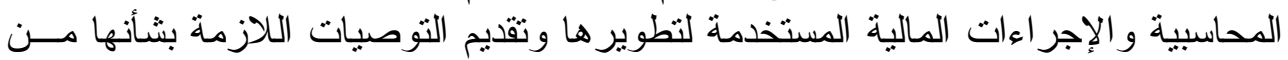

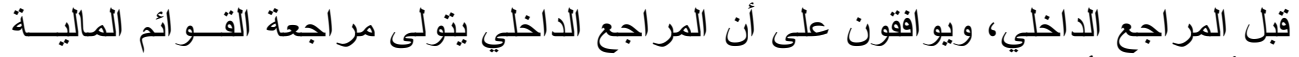

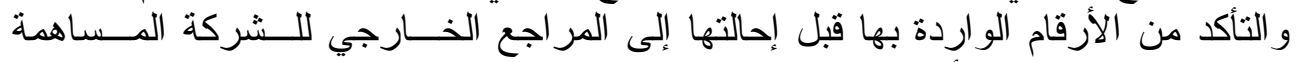

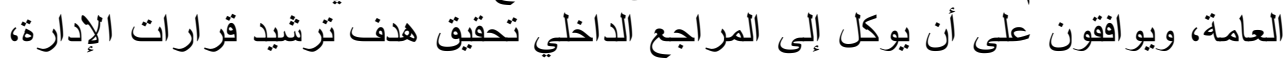

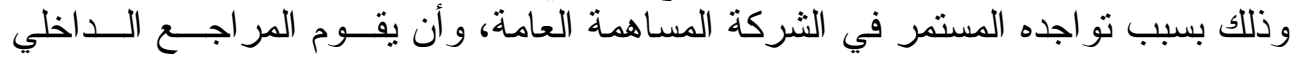

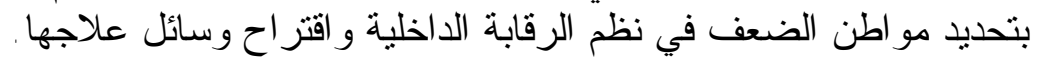

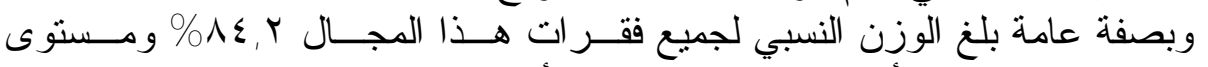

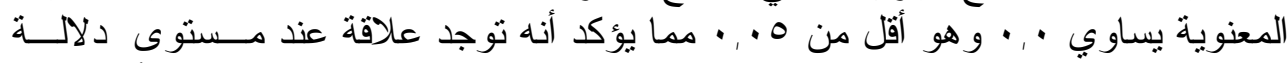

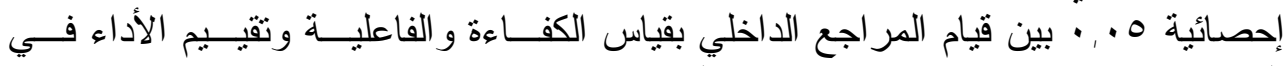

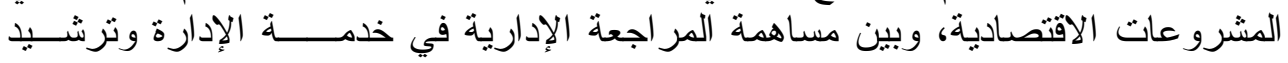

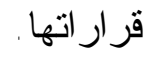

\section{الجدول}

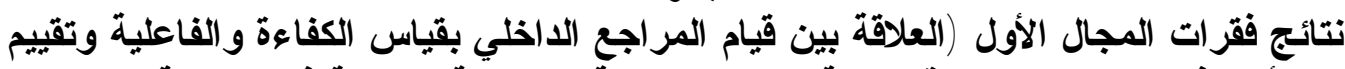

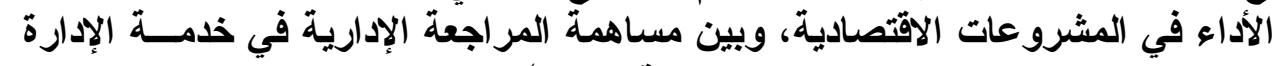

وترشيد قر ار اتها)

\begin{tabular}{|c|c|c|c|c|c|c|}
\hline 的: & 芧 & 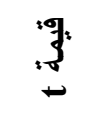 & 牙霓; & 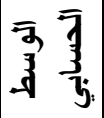 & الفقرات & 寻 \\
\hline$\varepsilon$ & $\because \cdot$ & $\curlyvee \wedge, \wedge \Lambda$ & $\wedge q, \varepsilon$ & $\varepsilon, \varepsilon V$ & 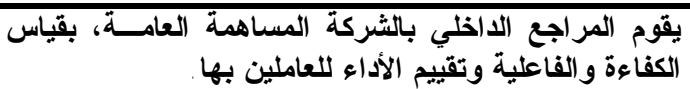 & 1 \\
\hline$r$ & $\because$ & $\curlyvee \wedge, \wedge \wedge$ & $91, \varepsilon$ & $\varepsilon, \Delta V$ & 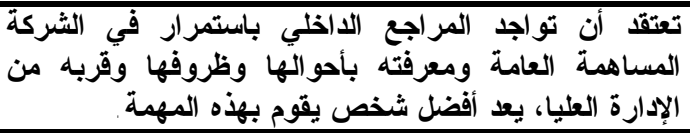 & $r$ \\
\hline
\end{tabular}




\begin{tabular}{|c|c|c|c|c|c|c|}
\hline 浔: & 变 & :णु: & 可事 & 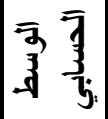 & الفقر ات & 3 \\
\hline 1. & $\cdot$, & $r Y, Y T$ & $\wedge r, r$ & $\varepsilon, 1 T$ & 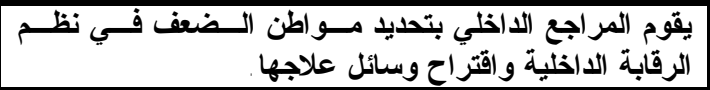 & $r$ \\
\hline$\varepsilon$ & $\because \cdot$ & $r \wedge, \wedge \wedge$ & $\wedge \eta, \varepsilon$ & $\varepsilon, \leqslant V$ & 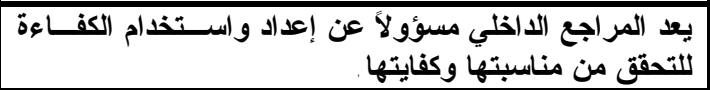 & $\varepsilon$ \\
\hline$\Lambda$ & $\because$ & $r q, 91$ & $\wedge \varepsilon$, & $\varepsilon, Y$. & 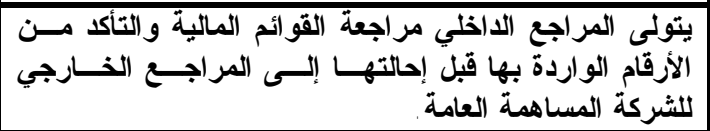 & 0 \\
\hline 1 & $\cdot$, & $m, v \leq$ & $q r_{1} \cdot$ & $\varepsilon, 7$. & 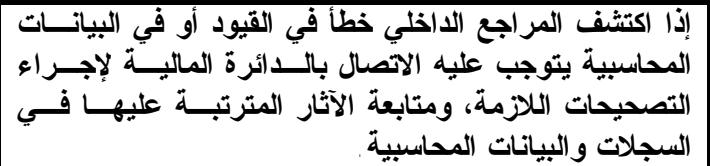 & 7 \\
\hline$r$ & 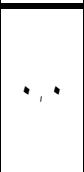 & $r v, r$. & $9 \cdot, 7$ & $\varepsilon, O r$ & 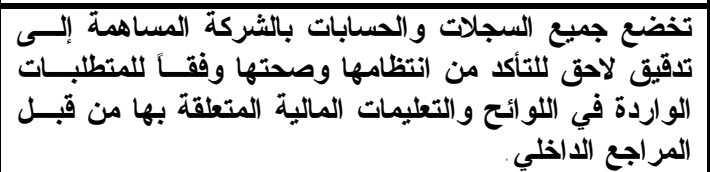 & V \\
\hline$\varepsilon$ & 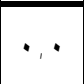 & $r \Delta, \wedge r$ & $\wedge q, \varepsilon$ & $\varepsilon, \varepsilon V$ & 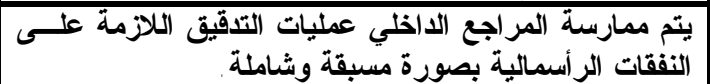 & $\Lambda$ \\
\hline 7 & $\because \cdot$ & $r \vee, \wedge \wedge$ & $\wedge \wedge$, & $\varepsilon, \varepsilon$. & 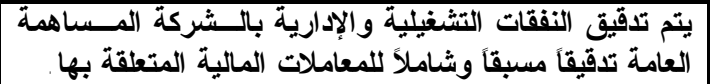 & 9 \\
\hline$r$ & $\cdot$, & $r v, r$. & $9 \cdot, 7$ & $\varepsilon, O r$ & 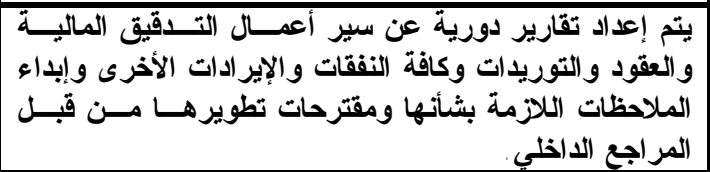 & 1. \\
\hline V & $\because$ & $r v, 19$ & $\wedge \neg, \wedge$ & $\varepsilon, r \leq$ & 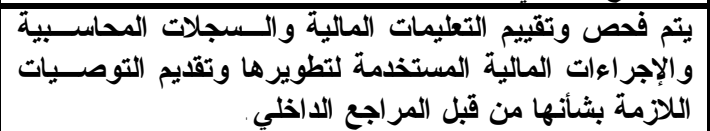 & 11 \\
\hline$r$ & $\because$ & $r \cdot, \cdot v$ & $9 \cdot, 7$ & $\varepsilon, O r$ & 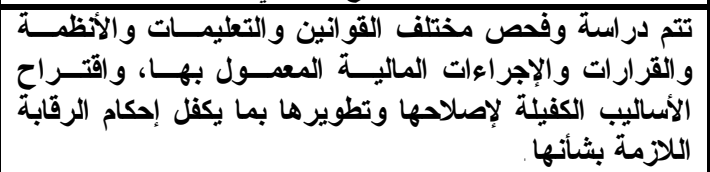 & Ir \\
\hline 0 & 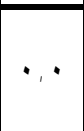 & $r \Delta, \wedge r$ & $\wedge q, r$ & $\{, \leqslant 7$ & 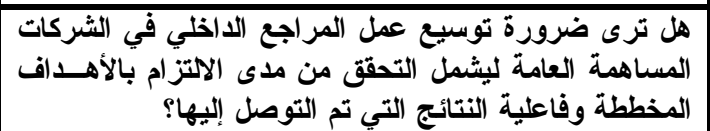 & $1 \%$ \\
\hline 9 & 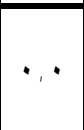 & $I V, r q$ & $\wedge r, \wedge$ & $\{, 1 \leqslant$ & 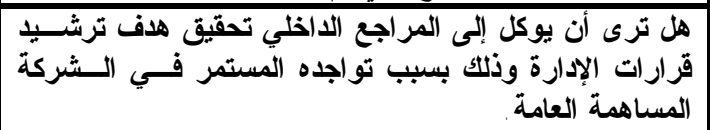 & $1 \varepsilon$ \\
\hline 11 & $\cdot$, & $r \cdot, .$. & $r q, \varepsilon$ & $1, \leqslant V$ & 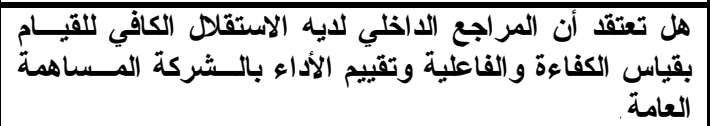 & 10 \\
\hline & 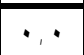 & $74, \wedge 1$ & $\Lambda \leqslant, \varepsilon$ & $\varepsilon, Y_{1}$ & جميع الفقرات & \\
\hline
\end{tabular}


"لا توجد علاقة عند مستوى دلالة إحصائية ه.,. بين قيام المراجع الخارجي

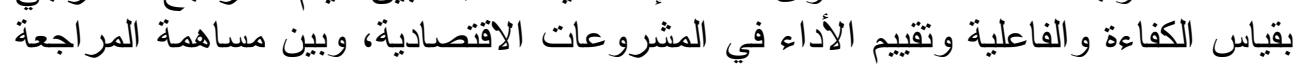

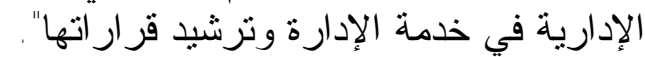

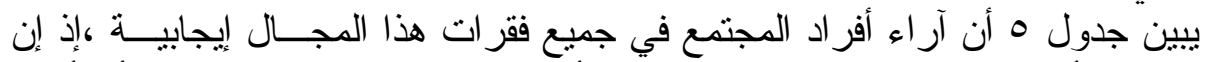

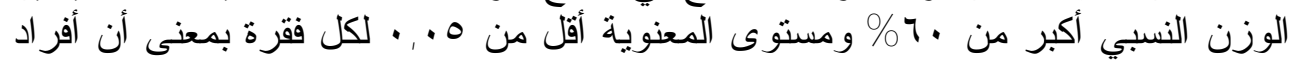

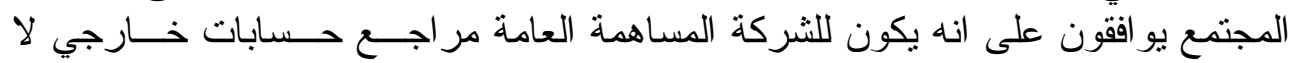

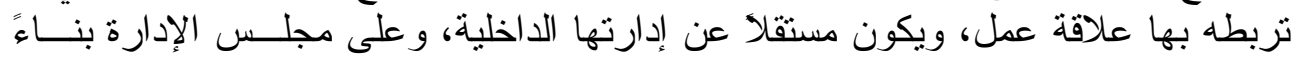

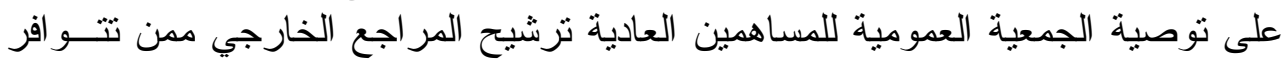

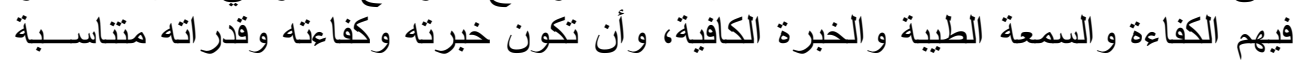

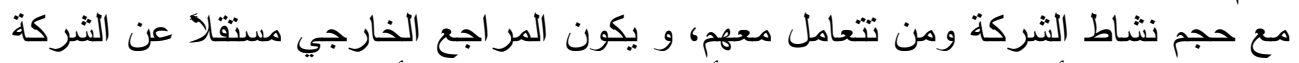

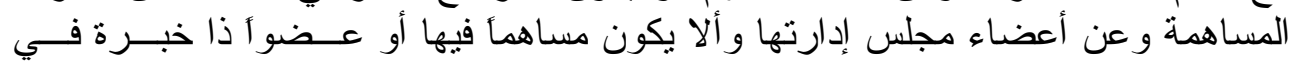

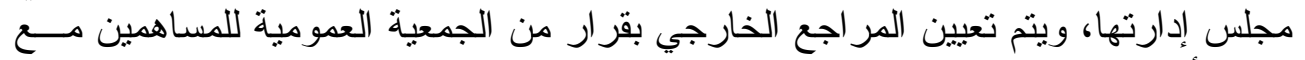

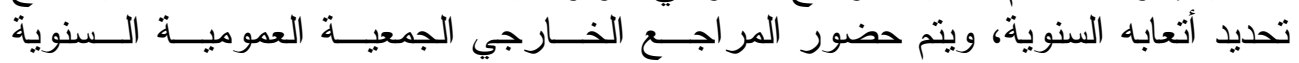

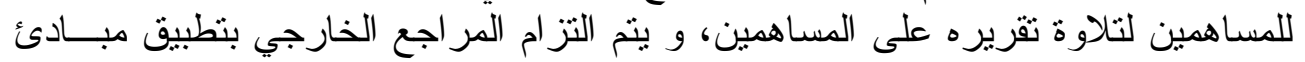

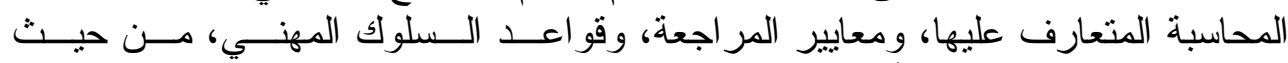

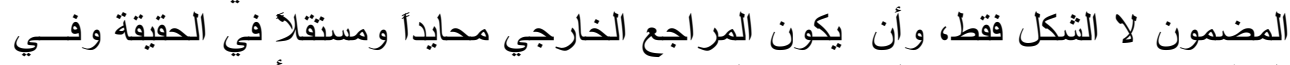

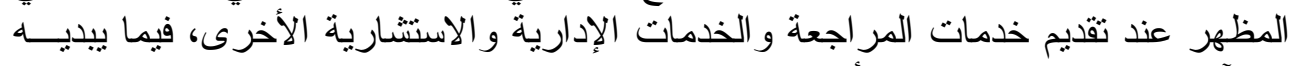

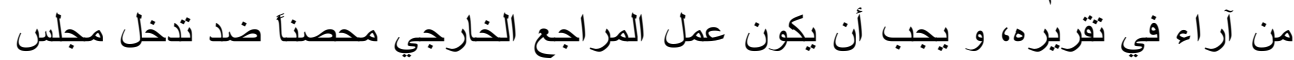

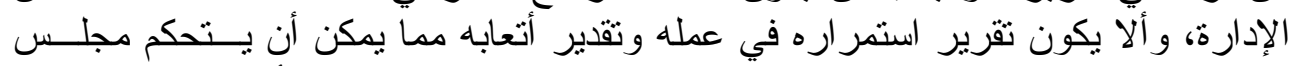

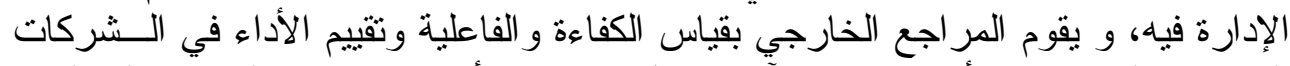

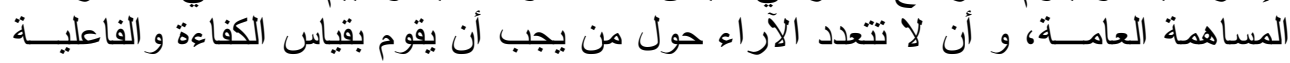

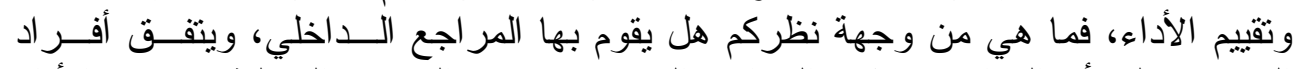

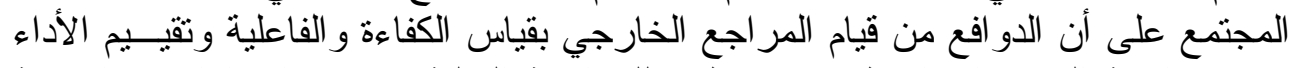

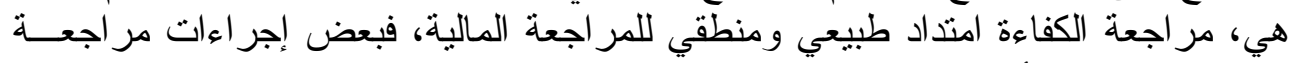

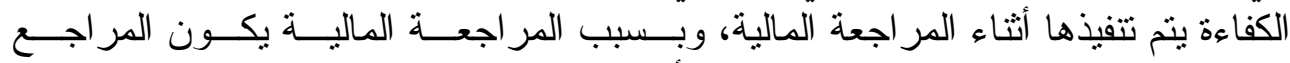

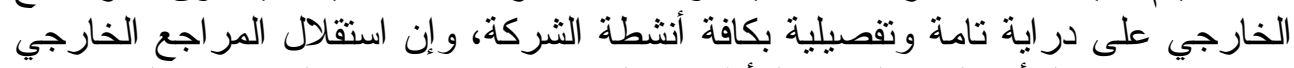

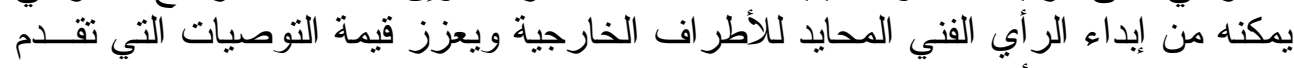

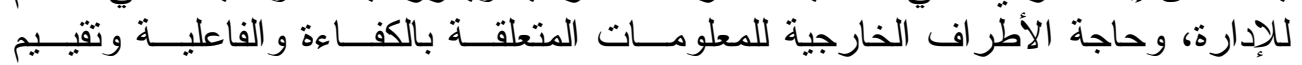

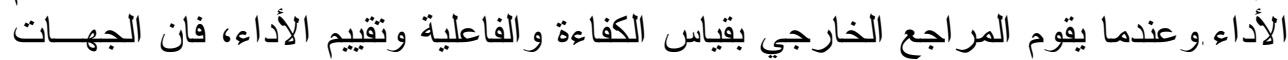

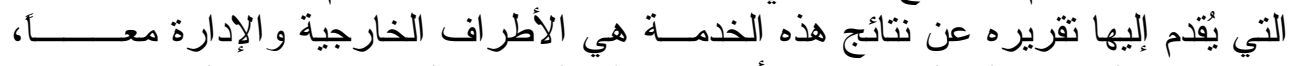

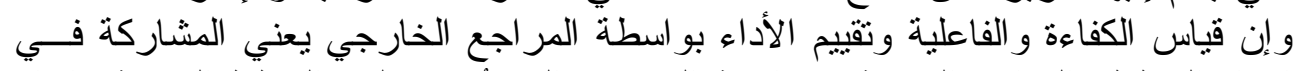

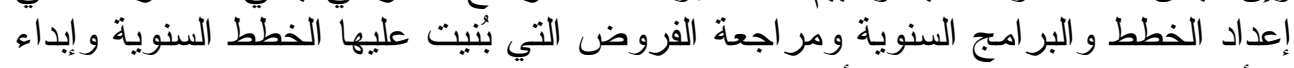

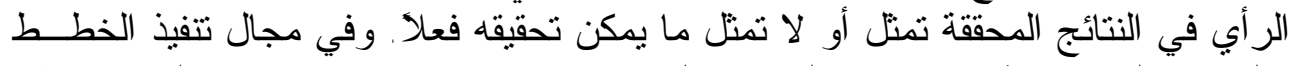

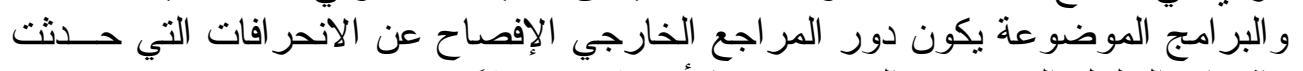

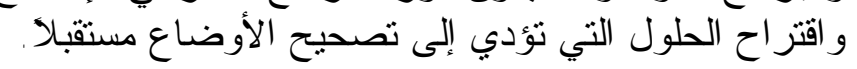

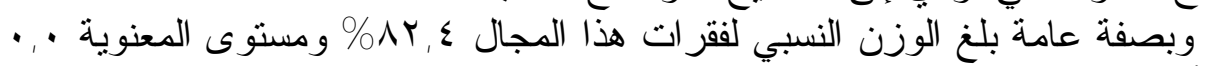

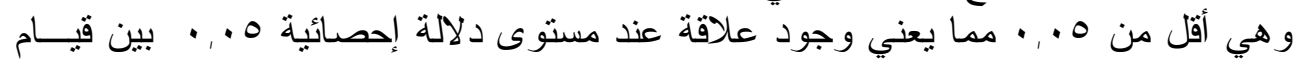




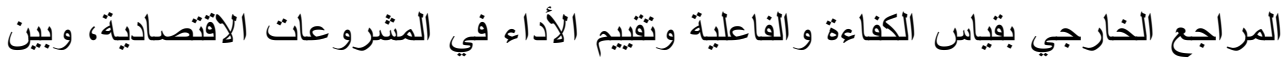

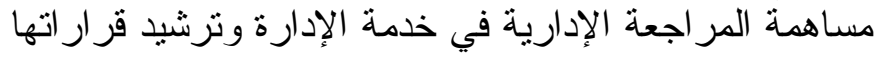

\begin{tabular}{|c|c|c|c|c|c|c|}
\hline \multicolumn{7}{|c|}{ 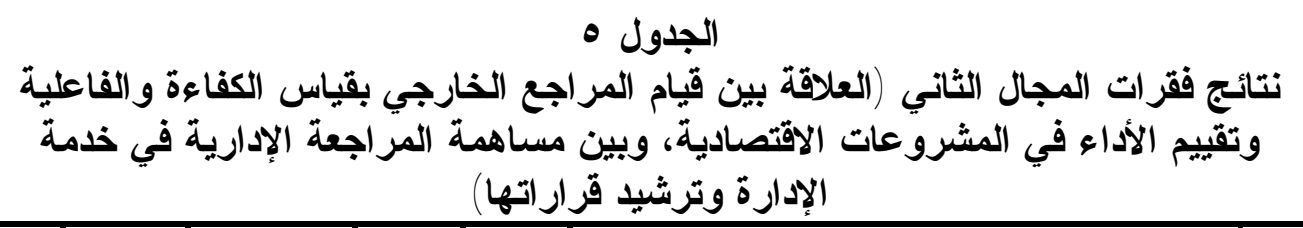 } \\
\hline 哥: & 勇 & :易; & 可 & $\overline{\bar{y}} \overline{3}$ & الفقر ات & 3 \\
\hline 1 & $\because \cdot$ & $\varepsilon r, \wedge \wedge$ & $94, r$ & $\varepsilon, 74$ & 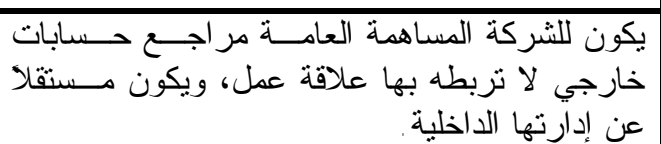 & 1 \\
\hline$r$ & $\because \cdot$ & $r v, r$. & $9 \cdot, 7$ & $\varepsilon, 0 r$ & 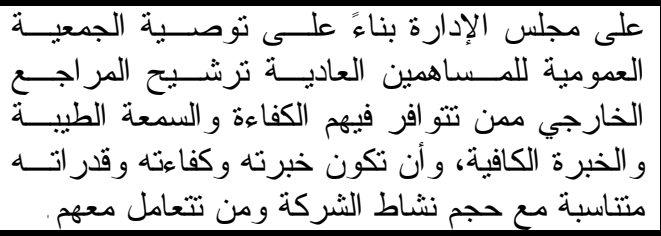 & r \\
\hline 1 & $\because \cdot$ & $\varepsilon r, \wedge \wedge$ & $9 r, Y$ & $\varepsilon, 74$ & 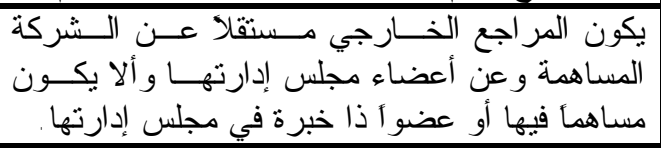 & $r$ \\
\hline v & $\because \cdot$ & $r \varepsilon, v q$ & $\wedge_{1} \cdot$ & $\varepsilon, \varepsilon \cdot$ & 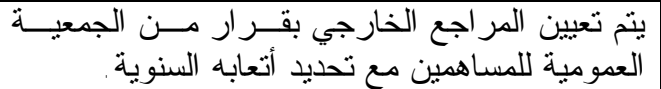 & $\varepsilon$ \\
\hline 9 & $\because \cdot$ & $19, \varepsilon V$ & $\wedge q, \cdot$ & $\varepsilon, r \cdot$ & 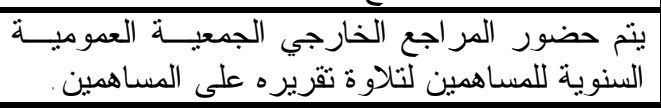 & 0 \\
\hline$\varepsilon$ & $\cdot \cdot$ & ro, & $\wedge q, \varepsilon$ & $\varepsilon, \varepsilon V$ & 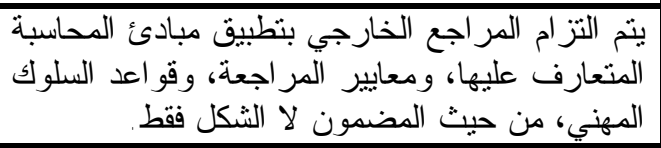 & 7 \\
\hline 0 & $\therefore$ & $r \varepsilon, V_{0}$ & $\wedge 9, \cdot$ & $\varepsilon, \leqslant 7$ & 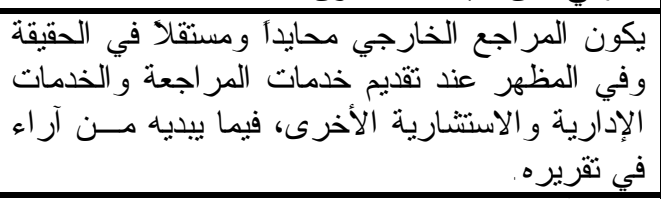 & V \\
\hline$\wedge$ & $\cdot \cdot$ & $r, 11$ & $\wedge 7,7$ & $\varepsilon, \mu r$ & 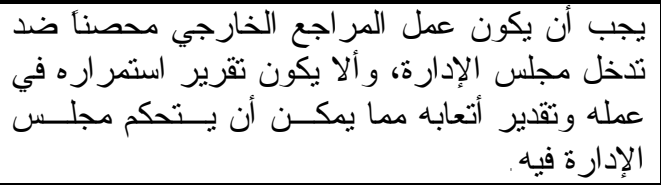 & $\wedge$ \\
\hline . & $\because \cdot$ & $19, \cdot r$ & $\Lambda 1, \varepsilon$ & $\varepsilon, \cdot v$ & 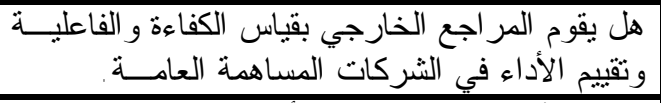 & 9 \\
\hline $1 T$ & $\therefore$ & $r r_{,} \varepsilon \Lambda-$ & $r \cdot, \varepsilon$ & $1,0 \mathrm{r}$ & 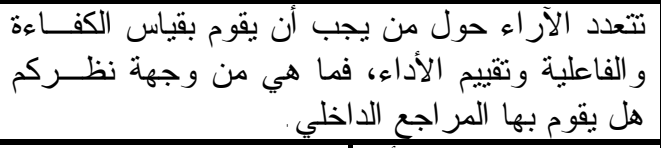 & 1. \\
\hline & & & & & إن كنــتن تؤيـــــون أن & 11 \\
\hline
\end{tabular}


الدكتور النعامي [N1]]

\begin{tabular}{|c|c|c|c|c|c|c|c|}
\hline 得: & 零 & :马ु" & 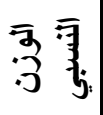 & $\overline{\bar{y}} \overline{3}$ & \multicolumn{2}{|c|}{ الفقرات } & 3 \\
\hline & & & & & 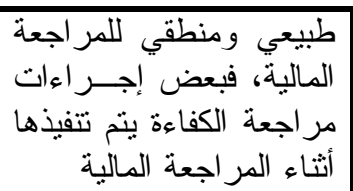 & \multirow{4}{*}{ 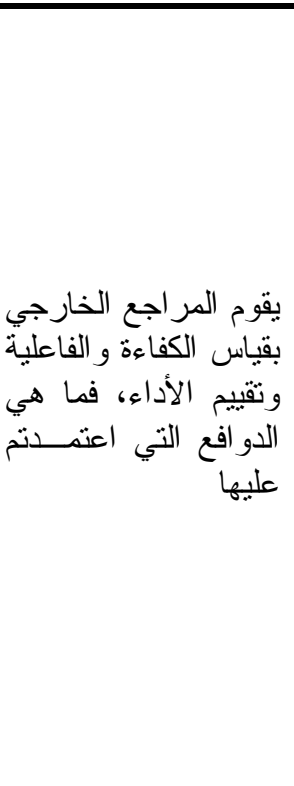 } & \\
\hline$\wedge$ & $\cdot \cdot$ & $r r, 11$ & $\wedge 7,7$ & $\varepsilon, r$ & 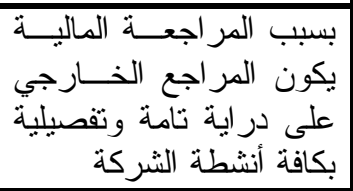 & & \\
\hline V & $\cdot \cdot$ & $r r, \wedge \leq$ & $\wedge \wedge, \cdot$ & $\varepsilon, \varepsilon$. & 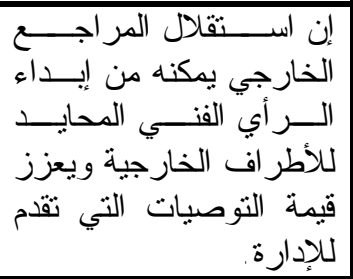 & & \\
\hline$r$ & $\because \cdot$ & $r_{0, \wedge \Lambda}$ & $9 \cdot, 7$ & $\varepsilon$, Or & 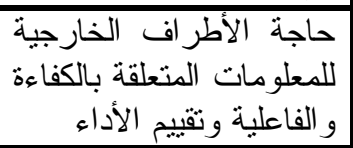 & & \\
\hline IT & $\because \cdot$ & $9,10-$ & or, & $r, T$ & الأطر اف الخارجية فقط & \multirow[b]{2}{*}{ 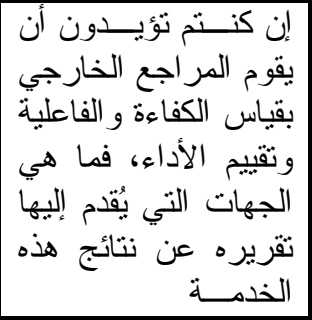 } & \multirow[b]{2}{*}{ ir } \\
\hline 1 & $\cdot \cdot \cdot$ & rr, & $9 r, r$ & $\varepsilon, 77$ & 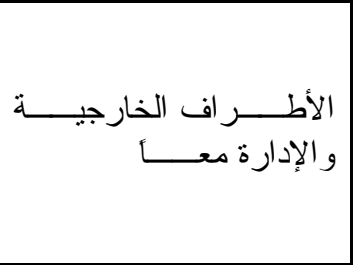 & & \\
\hline 1 & $\because \cdot$ & rT,AN & $9 r, r$ & $\varepsilon, 77$ & و المشاركة في إعداد الخطط & \multirow[b]{2}{*}{ 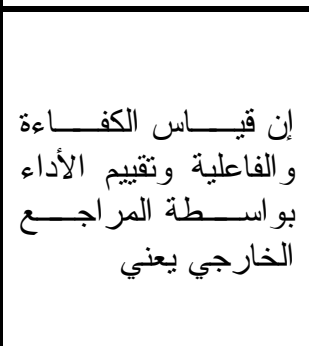 } & \multirow[b]{2}{*}{ ir } \\
\hline 7 & $\cdot \cdot$ & 18,17 & $\wedge \Lambda, \varepsilon$ & $\varepsilon, \varepsilon Y$ & 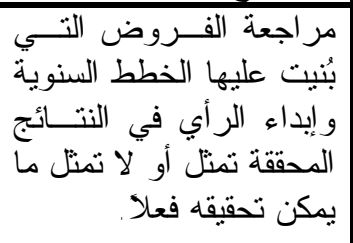 & & \\
\hline 11 & 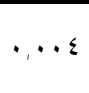 & $r, q Y-$ & $\infty 0, \wedge$ & $r, v q$ & 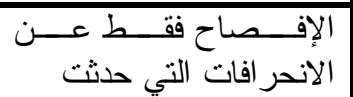 & \multirow{2}{*}{ 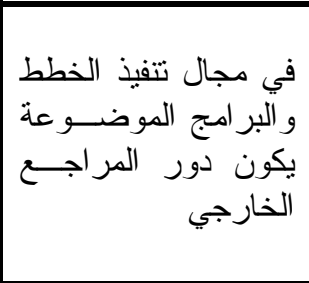 } & \multirow[b]{2}{*}{$1 \varepsilon$} \\
\hline 0 & $\cdot \cdot \cdot$ & $M r, .0$ & $\wedge 9, r$ & $\varepsilon, \varepsilon 7$ & 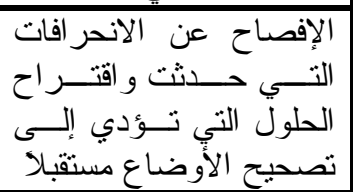 & & \\
\hline & $\because \cdot$ & $\Delta r, \wedge r$ & $\Lambda r, \Lambda$ & $\varepsilon, 1 \varepsilon$ & \multicolumn{3}{|c|}{ جميع الفقر ات } \\
\hline
\end{tabular}


"لا توجد علاقة عند مستوى دلالة إحصائية هـ. الأقسام المختلفة بالمنشأة، وبين مساهمة المراجعة الإدارة الإرية في خدمة الإدارة وترشيد

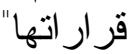

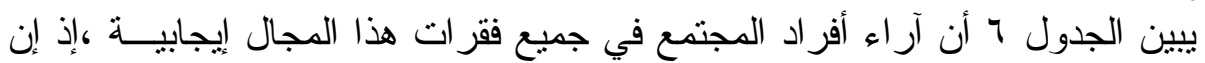

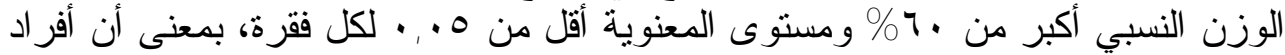

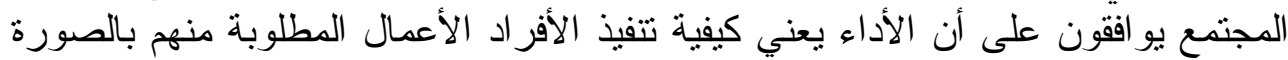

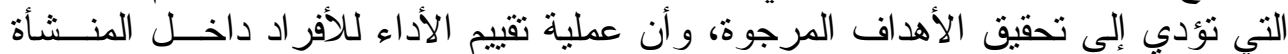
تؤُدي إلى الكثف عن العناصر الكفوءة في المو اقع الأكثر إنتاجية وتحديد العناصر التهي التهي

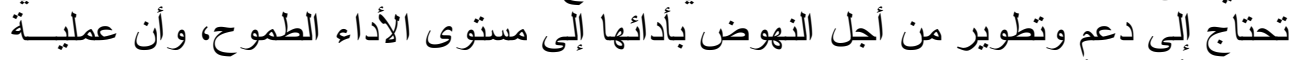

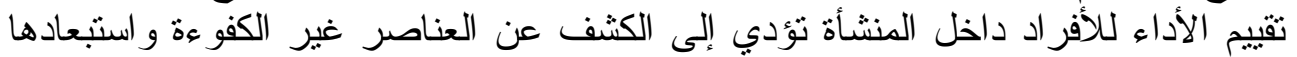

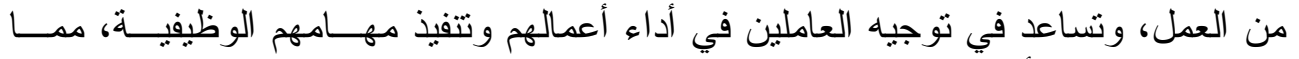

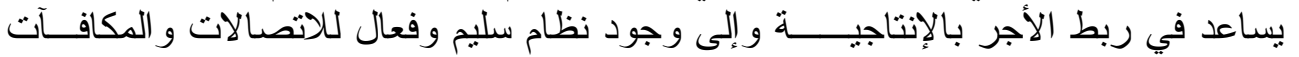

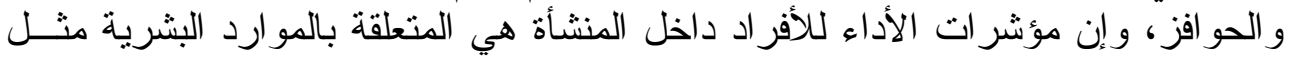

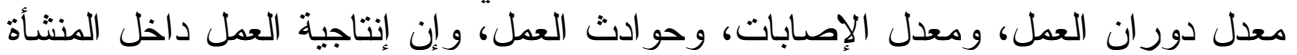

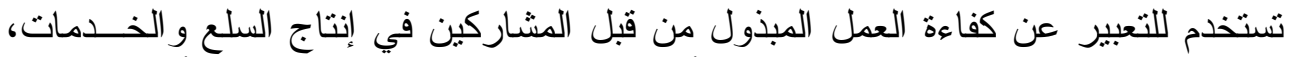

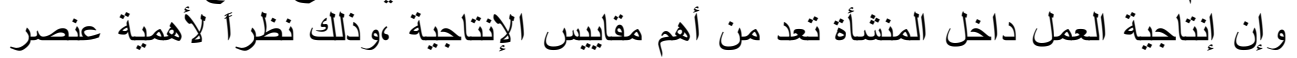

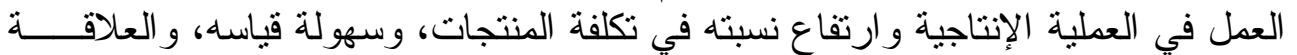

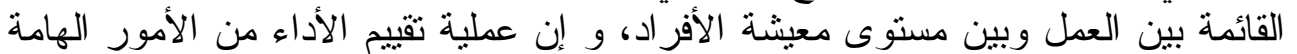

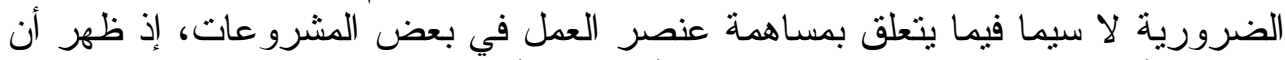
مساهمته أعلى من مساهمة بقية العناصر الأخرى كر أس المال الثابت في القيمة المضافة الفافة،

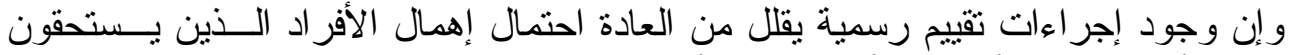

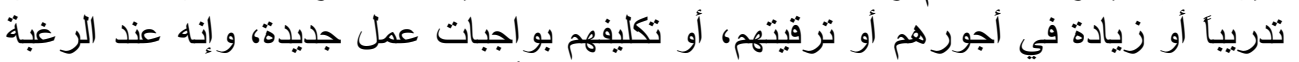

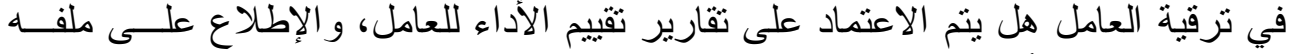

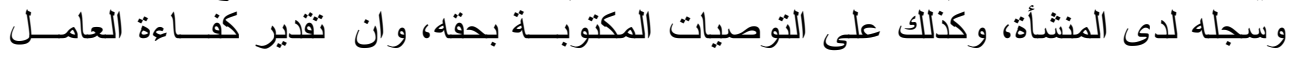

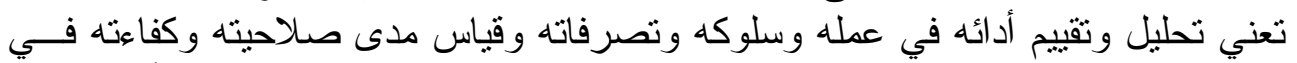

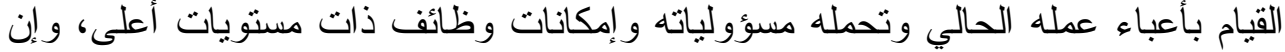

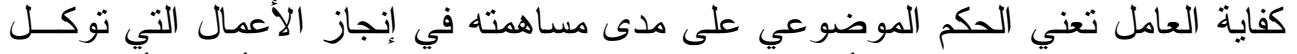

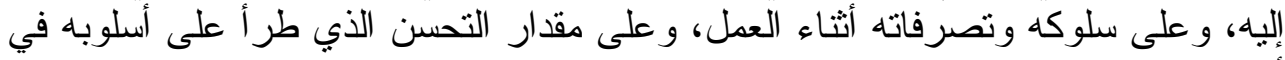

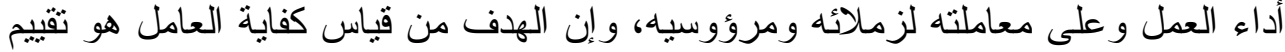

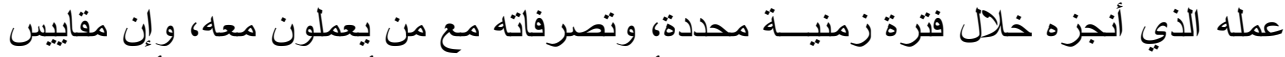

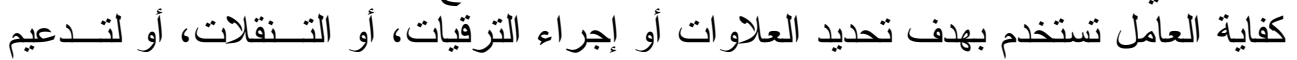

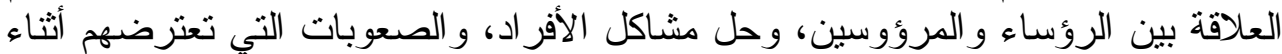

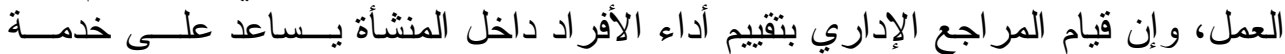

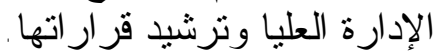

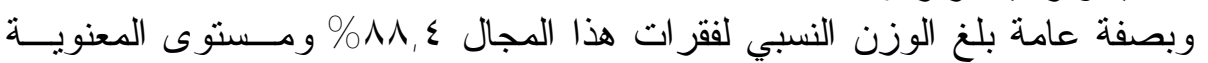

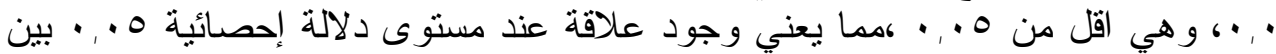


الدكتور النعامي [r·

تققيم أداء الأفر اد داخل الأقسام المختلفة بالمنشأة، وبين مساهمة المر اجعة الإداريــة فــي خدمة الإدارة وترشيد قر ار اتها.

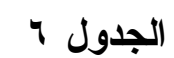

نتائج فقرات المجال الثالث (العلاقة بين تقييم أداء الأفراد داخل الأقسام المختلفة

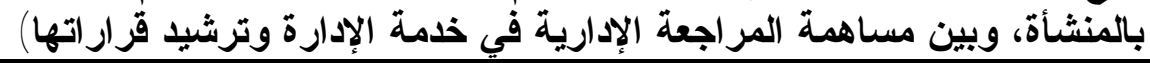

\begin{tabular}{|c|c|c|c|c|c|c|}
\hline 牙: & 勇 & :3: & $\overline{7} \overline{7}$ & $\overline{\overline{3}} \overline{\frac{7}{3}}$ & الفقر ات & 3 \\
\hline 7 & $\because \cdot$ & $r 0, \wedge r$ & $\wedge q, \varepsilon$ & $\varepsilon, \varepsilon V$ & منهم بالصورة التي تيؤدي إلى تلى تحقيق الأفراء الأهداف المرجية المطلوبة & 1 \\
\hline$\varepsilon$ & $\because \cdot$ & $r v, r$. & $9 \cdot, 7$ & $\varepsilon$, or & 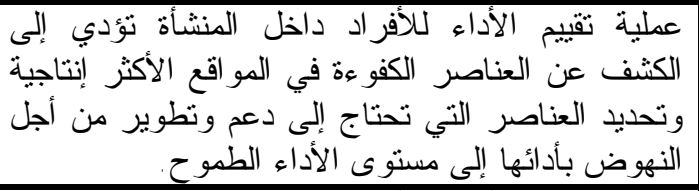 & r \\
\hline 11 & $\because \cdot$ & $r v, 19$ & $\wedge \neg, \wedge$ & $\varepsilon, \Gamma \varepsilon$ & 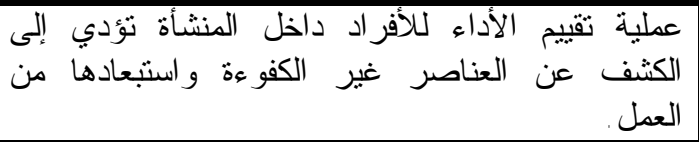 & $r$ \\
\hline 17 & $\because \cdot$ & $r V, O V$ & $\wedge r, T$ & $\varepsilon, 1 T$ & 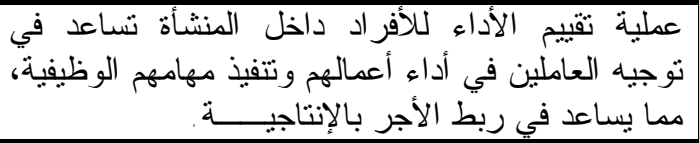 & $\varepsilon$ \\
\hline$r$ & $\because \cdot$ & $r \cdot, r r$ & $9 \cdot, \wedge$ & $\{, 0\}$ & 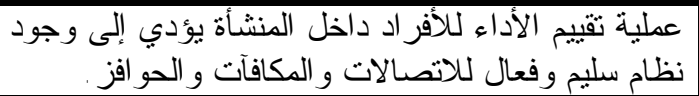 & 0 \\
\hline 1 & $\because \cdot$ & $\Gamma, V \varepsilon$ & $q r_{1} \cdot$ & $\varepsilon, 7$. & 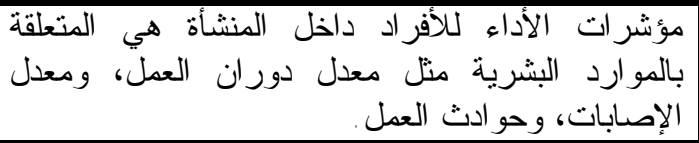 & 7 \\
\hline V & $\because \cdot$ & $r \wedge, V V$ & $\wedge q, r$ & $\varepsilon, \varepsilon 7$ & 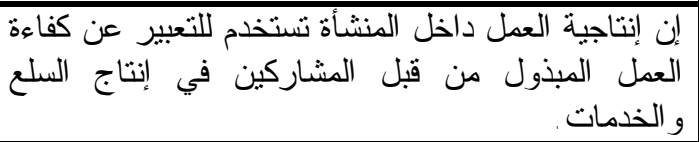 & $v$ \\
\hline 10 & $\because$ & $r 7,9)$ & $\wedge \varepsilon$, & $\varepsilon, Y$. & 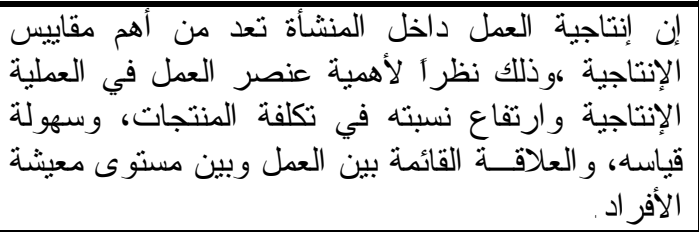 & $\Lambda$ \\
\hline$\wedge$ & $\because \cdot$ & $r \wedge, V V$ & $\wedge q, r$ & $\varepsilon, \varepsilon\rceil$ & 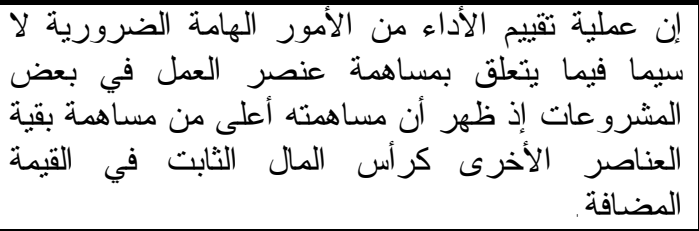 & 9 \\
\hline 9 & $\because$ & $r \wedge, V \vee$ & $\wedge q, r$ & $\varepsilon, \varepsilon\rceil$ & 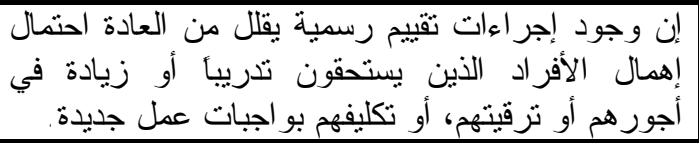 & 1. \\
\hline
\end{tabular}




\begin{tabular}{|c|c|c|c|c|c|c|}
\hline 牙 & 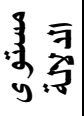 & :9.9: & $\overline{7} \overline{7}$ & $\overline{\mathfrak{z}} \overline{\mathfrak{y}}$ & الفقر ات & 3 \\
\hline IT & $\cdot \cdot$ & $r v, 19$ & $\wedge \neg, \wedge$ & $\varepsilon, \Gamma \varepsilon$ & 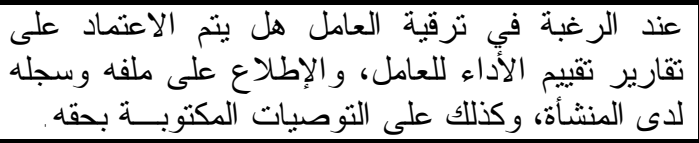 & 11 \\
\hline $1 T$ & $\because \cdot$ & $r v, 19$ & $\wedge \neg, \wedge$ & $\varepsilon, \Gamma \varepsilon$ & 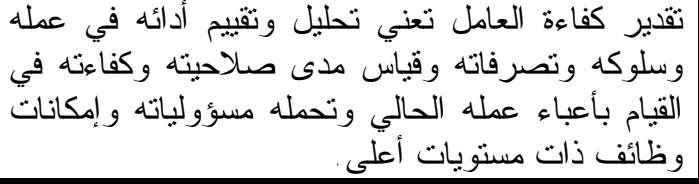 & Ir \\
\hline r & $\because \cdot$ & $\Gamma, V \varepsilon$ & $q r_{1} \cdot$ & $\varepsilon, 7$. & 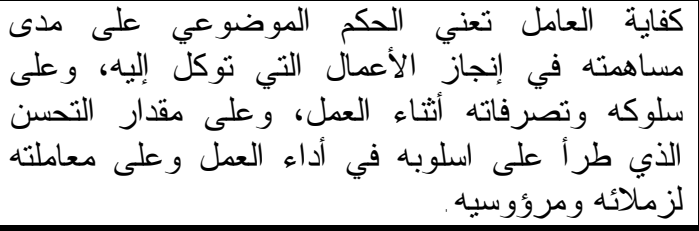 & $1 \%$ \\
\hline $1 \cdot$ & $\because \cdot$ & $r \wedge, V V$ & $\wedge q, r$ & $\varepsilon, \leqslant 7$ & 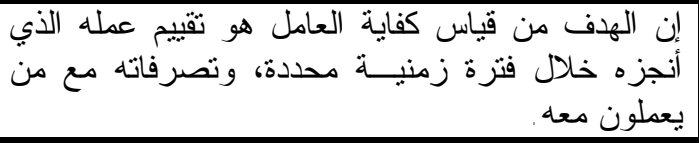 & $1 \varepsilon$ \\
\hline 0 & $\because \cdot$ & $r 7, \wedge r$ & $9 \cdot, \cdot$ & $\varepsilon, 0$ & 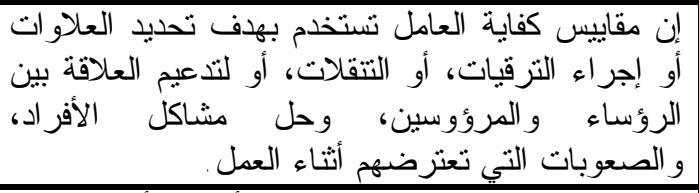 & 10 \\
\hline $1 \varepsilon$ & $\because \cdot$ & $r V, 1 \varepsilon$ & $\wedge \neg\rceil$, & $\varepsilon, \mu$ & 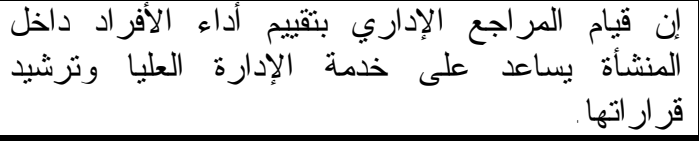 & 17 \\
\hline & $\because \cdot$ & or, $\leq 0$ & $\wedge \wedge, \varepsilon$ & $\varepsilon, \varepsilon Y$ & جميع فقر ات المجال & \\
\hline
\end{tabular}

الفرضية الرابعة

"لا توجد علاقة عند مستوى دلالة إحصائية ه.,.•، بين المعوقات في العمليات

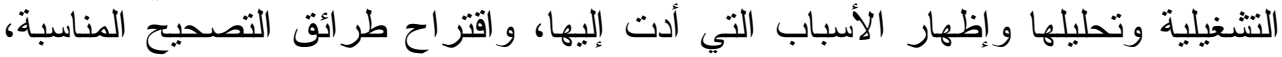

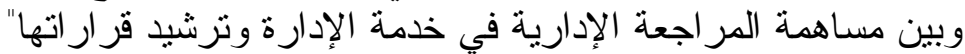

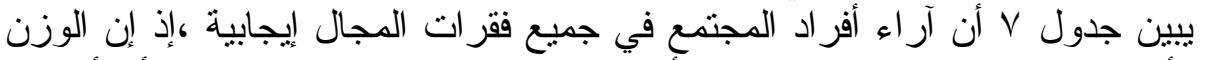

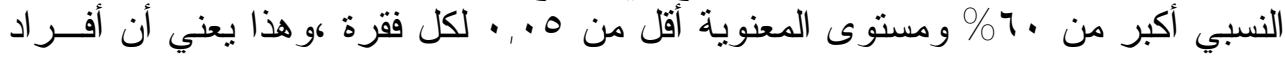

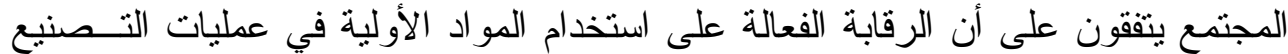

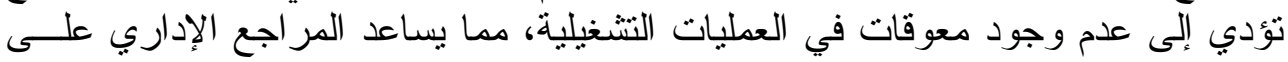

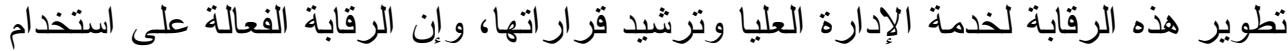

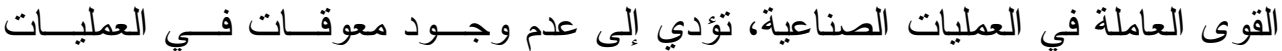

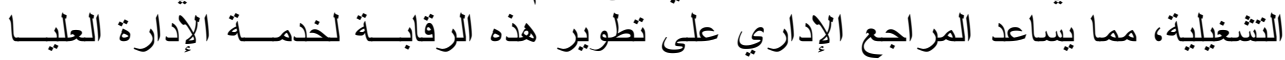

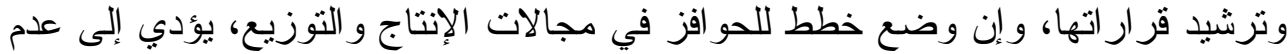

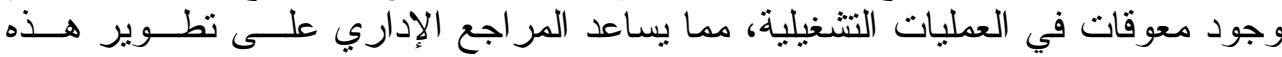




\section{الدكتور النعامي [rren}

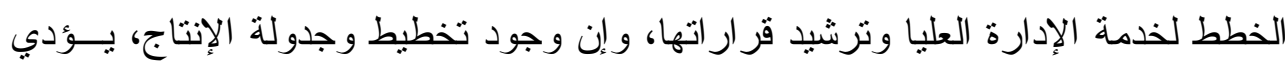

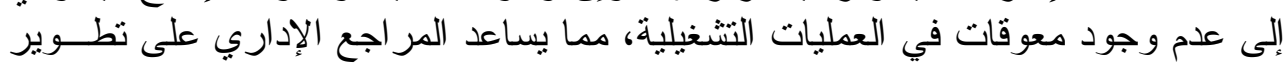

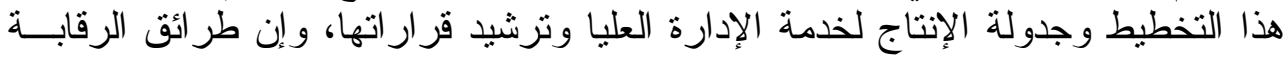

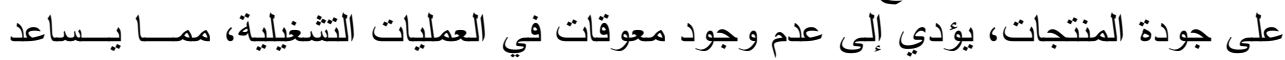

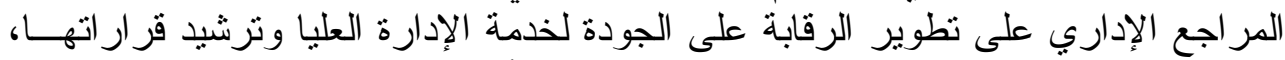

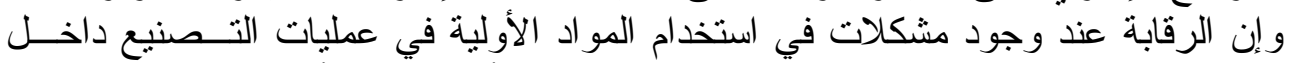

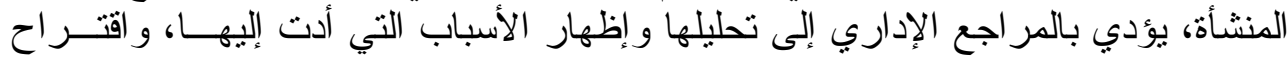

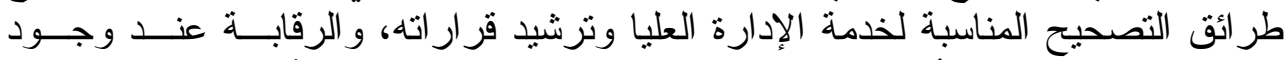

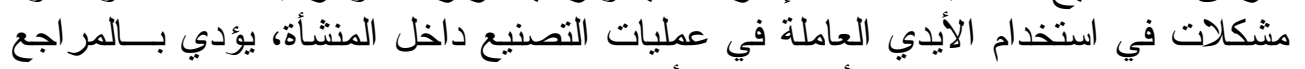

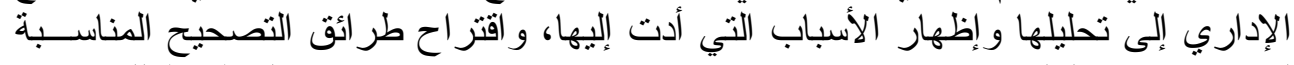

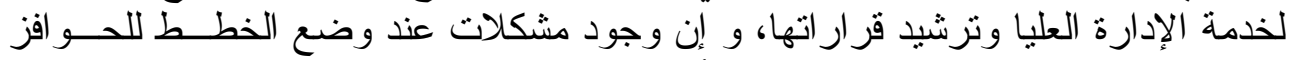

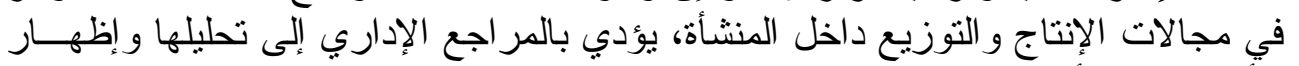

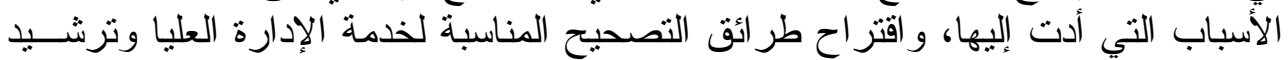

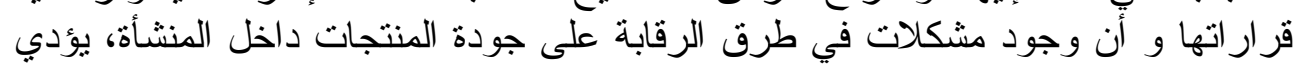

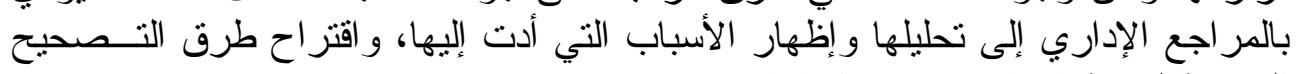
المناسبة لخدمة الإدارة وترشيد قرار الهاريا.

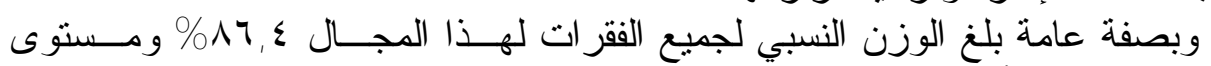

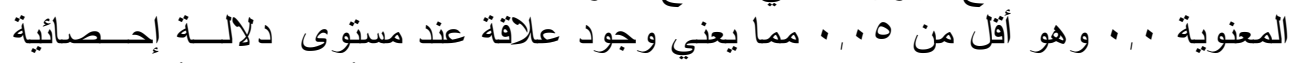

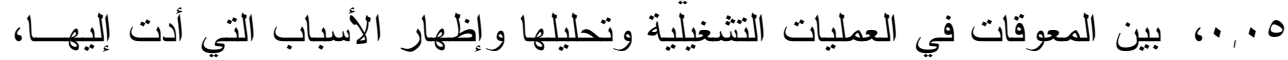
و اقتر اح طر ائق التصحيح المناسبة، وبين مساهمة المر اجعة الإدارية فــي خدمســة الإدارة الإن وترشيد قرار اتها.

\section{V الجدول}

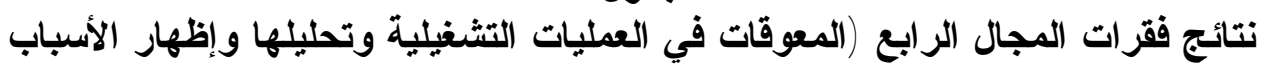

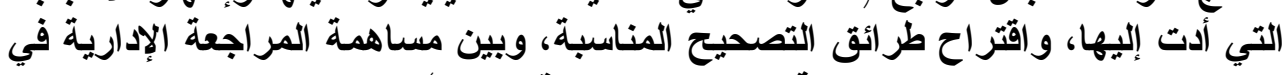
خدمة الإدارة وترشيد قرار اتها)

\begin{tabular}{|c|c|c|c|c|c|c|}
\hline 牙。 & 多 & "昌" & 牙霓 & 可 & الفقرات & 3 \\
\hline 1 & $\therefore$ & $r \wedge, \wedge \Lambda$ & $\wedge 9, \varepsilon$ & $\varepsilon, \varepsilon V$ & 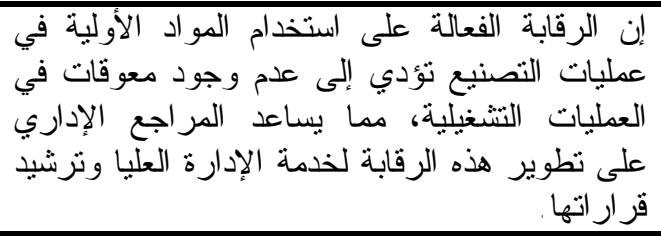 & 1 \\
\hline$r$ & $\therefore$ & $r r, T r$ & $10, \varepsilon$ & $\varepsilon, r V$ & 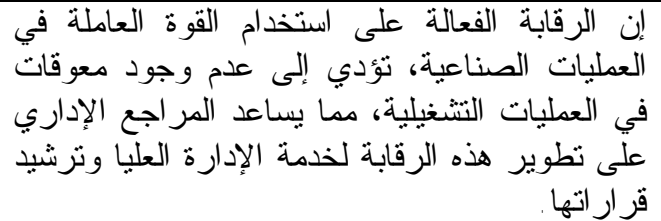 & r \\
\hline
\end{tabular}




\begin{tabular}{|c|c|c|c|c|c|c|}
\hline 㝵: & 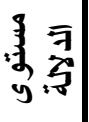 & "웜 & 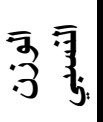 & 亏) & الققر ات & $q$ \\
\hline 0 & $\because \cdot$ & $r, r_{1}$ & $\wedge \varepsilon, \cdot$ & $\varepsilon, Y$. & 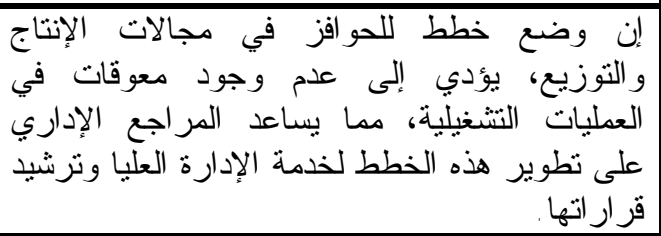 & $r$ \\
\hline 7 & $\because \cdot$ & $r r, r q$ & $\wedge r, \wedge$ & $\varepsilon, 19$ & 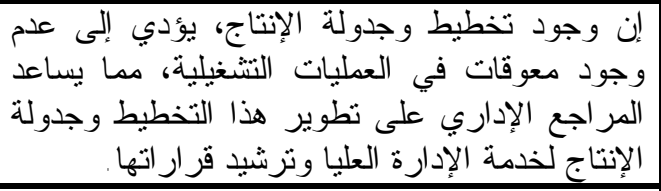 & $\varepsilon$ \\
\hline$r$ & $\because \cdot$ & $r T, \wedge \varepsilon$ & $\wedge \Lambda_{1}$. & $\varepsilon, \varepsilon$. & 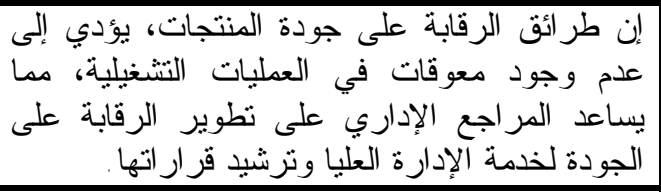 & 0 \\
\hline$r$ & $\because \cdot$ & $r T, q Y$ & $\wedge \wedge$, & $\varepsilon, \varepsilon$. & 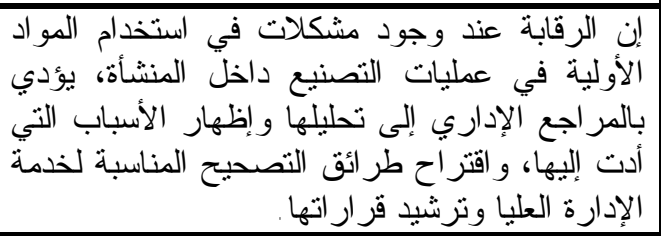 & 1 \\
\hline$r$ & $\because \cdot$ & $r T, q T$ & $\Lambda \Lambda$, & $\varepsilon, \varepsilon$. & 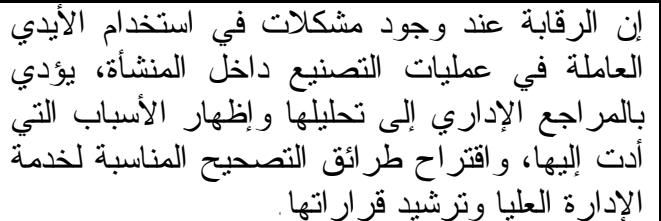 & V \\
\hline$\varepsilon$ & $\because \cdot$ & $r r, 09$ & $10, r$ & $\left\{, Y_{Y}\right.$ & 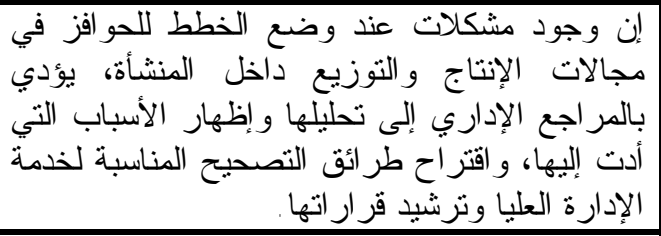 & $\wedge$ \\
\hline$\varepsilon$ & $\because \cdot$ & 19,11 & $10, r$ & $\varepsilon, Y \uparrow$ & 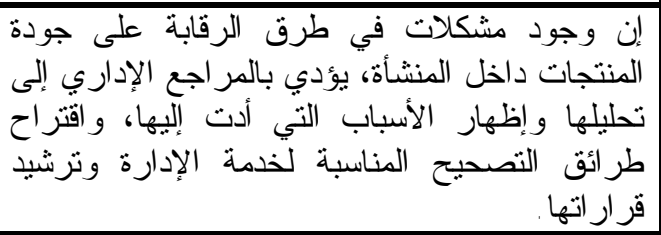 & 9 \\
\hline & $\because \cdot$ & $r r, T)$ & $\wedge 7, \varepsilon$ & $\varepsilon, T I V V$ & جميع فقرات هذا المجال & \\
\hline
\end{tabular}


- لم تلق المر اجعة الإدارية الاهتمام الكافي حتى الآن من الجمعيات المهنية للمحاسبية

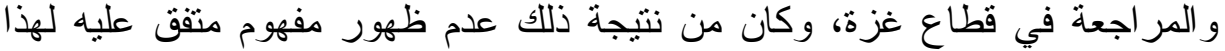

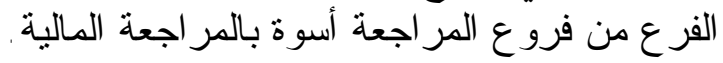

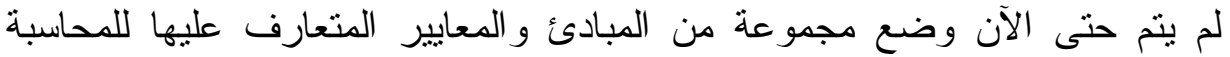

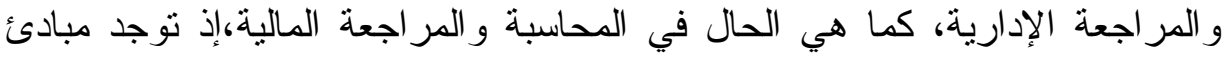

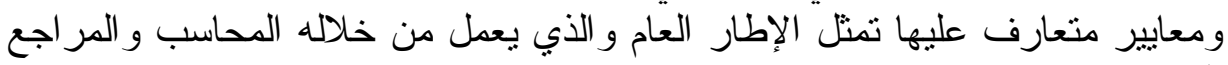

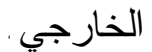

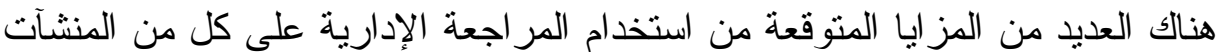

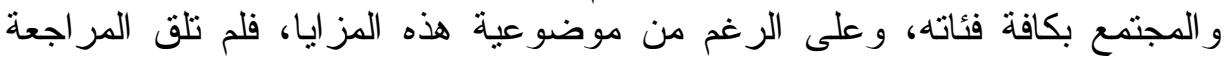
الإدارية حتى الآن الاهتمام الكافي.

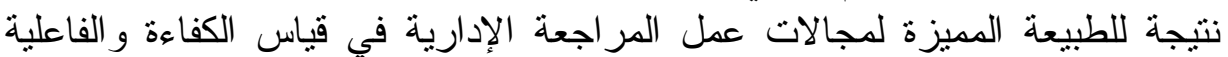

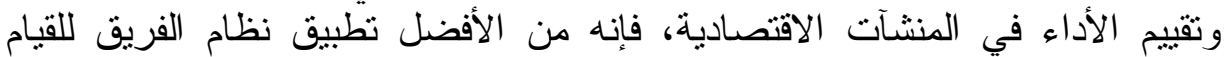

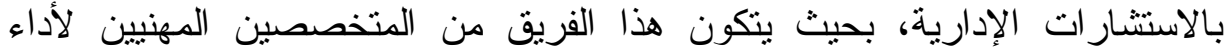

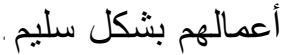

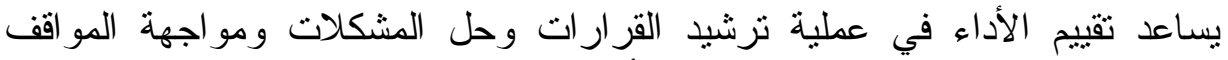

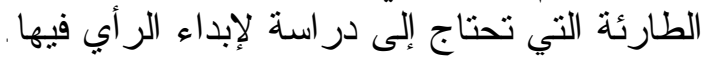

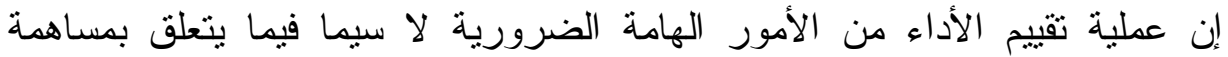

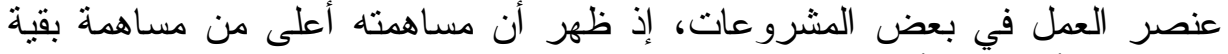

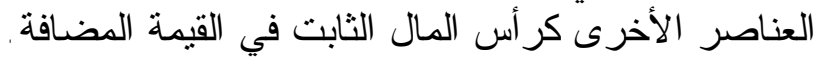

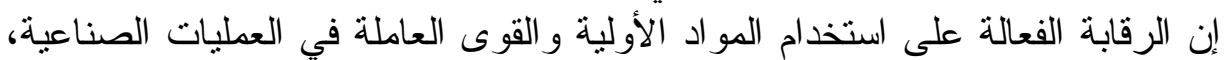

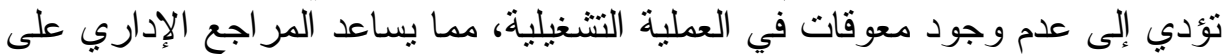
تطوير هذه الرقابة لخدمة الإدارة العليا وترشيد قرئ فرار التها.

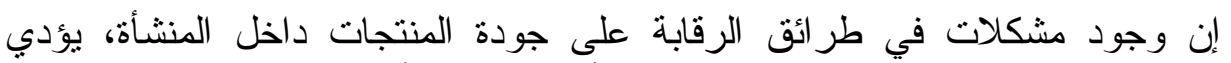

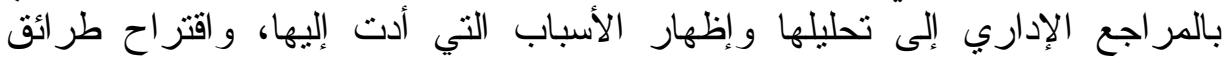

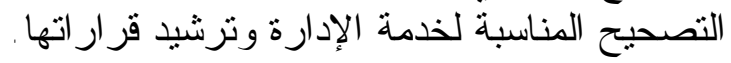

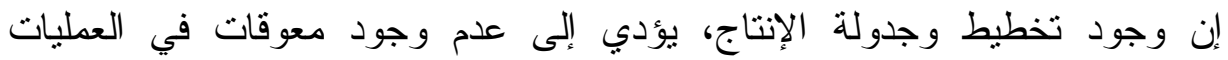

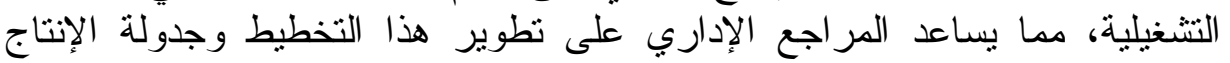
لخدمة الإدارة العليا وترشيد قرار اتها . ل الآداري

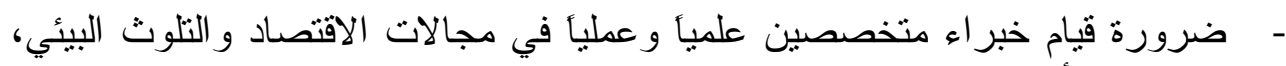

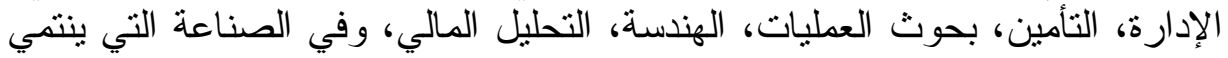

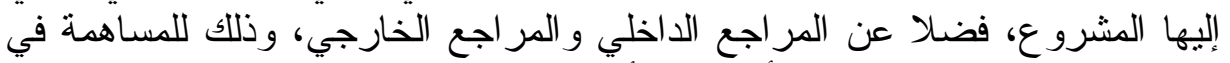

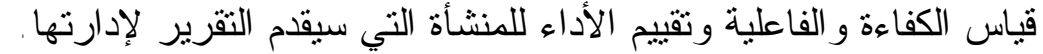

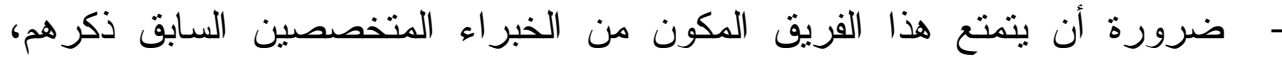
بالحياد و الاستقال عند قيامهم بتتفيذ المهام الموكلة إليهم. 


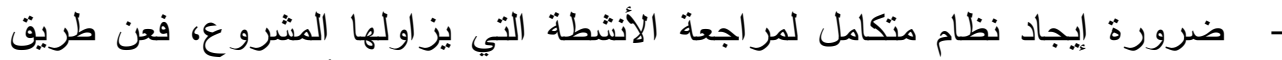

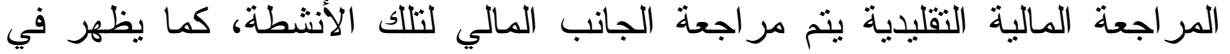

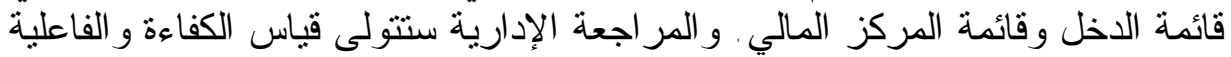

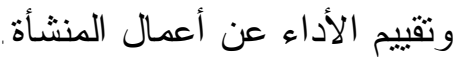
اكتثاف أية أخطاء أو انحر افات في التتفيذ والعمل على اتخاذ الإجر اءات التصحيحية

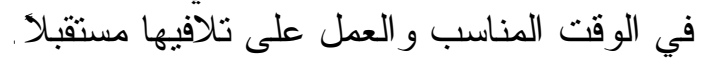

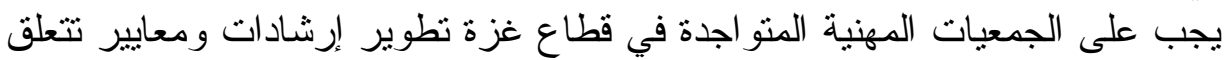
بقياس الكفاءة و الفاعلية وتقييم الأداء للمشروعات التية الاقتصادية.

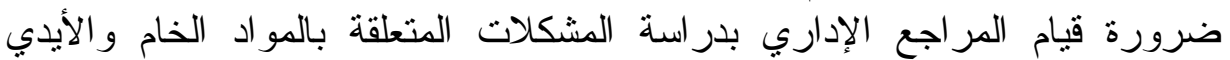

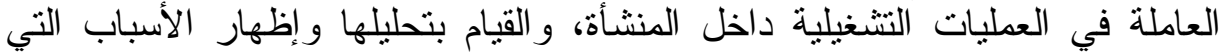
أدت إليها، و اقتر اح طر ائق التصحيح المناسبة، لخدمة الإدارة العليا وترشيد قرار التها التها.

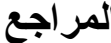 \\ أولاً -المر اجع باللغة العربية}

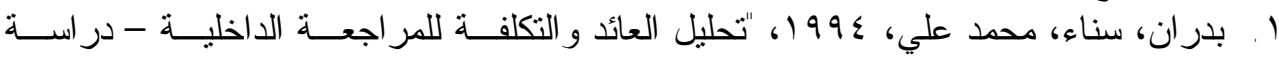

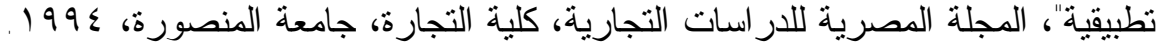

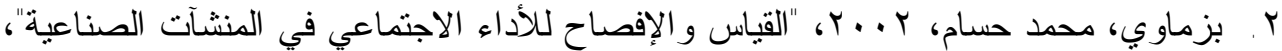

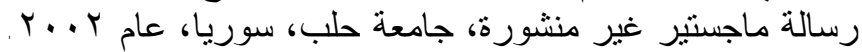

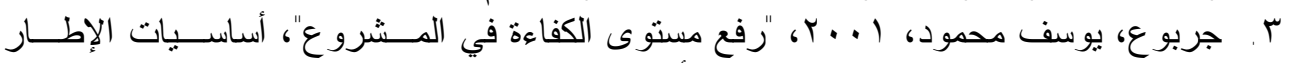

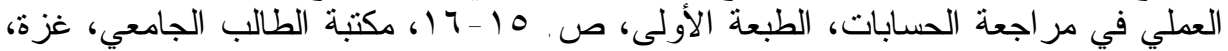

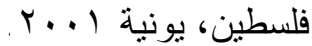

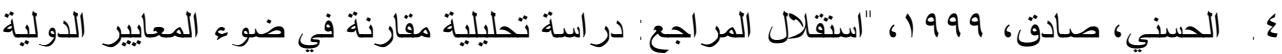

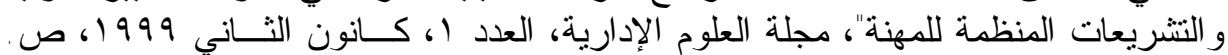

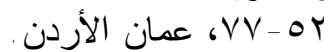

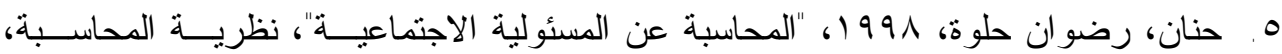
الطبعة الأولى، الناثر مكتبة الثقافة للنشر و التوزيع، عمان، النقان، الأردن.

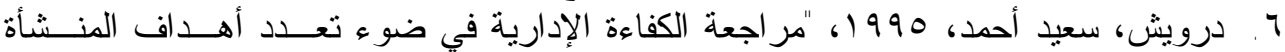

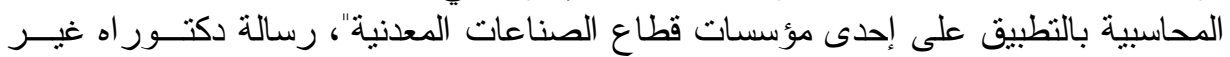

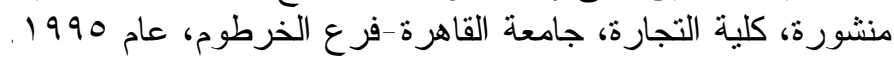

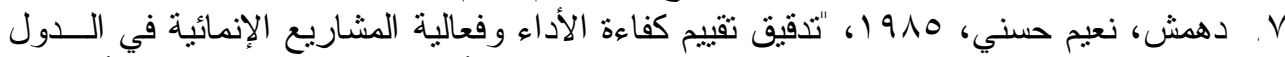

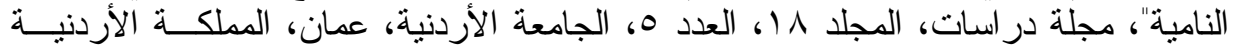

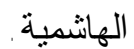

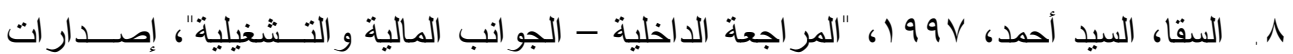

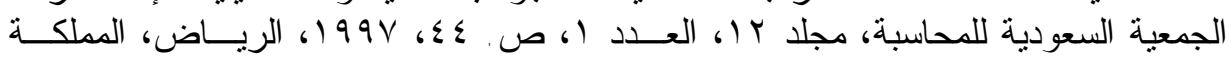
العربية السعودية.

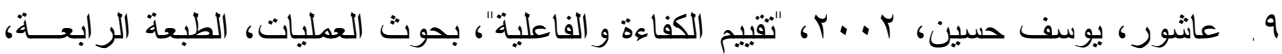

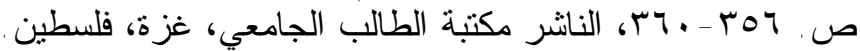




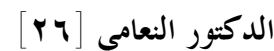

• 1 ـ العبادي، مصطفى ر اثند، 997 1، "دور المر اجع الخارجي في مر اجعة الكفــــاءة و الفاعليـــة

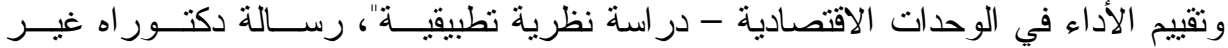

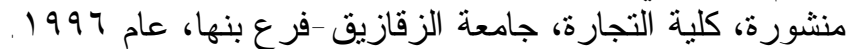

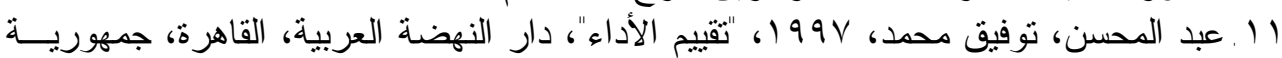
مصر العربية.

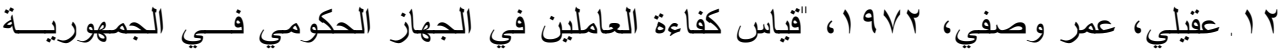

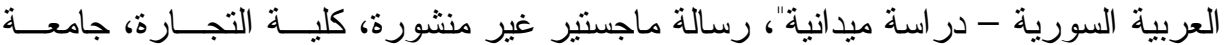
القاهرة، جمهورية مصر العربة العربية.

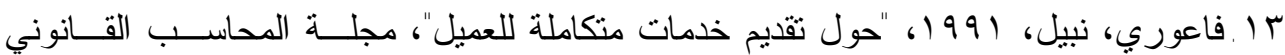

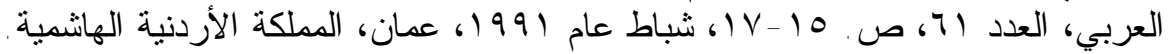

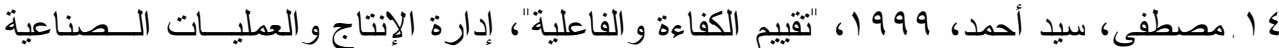

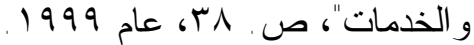

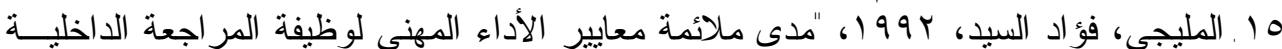

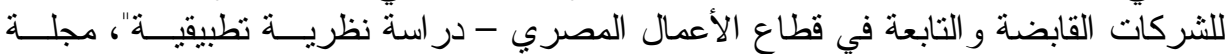

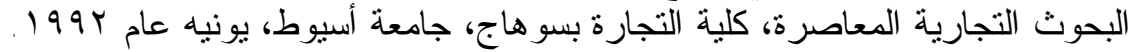

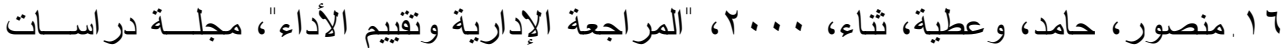

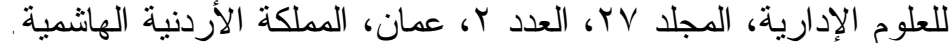

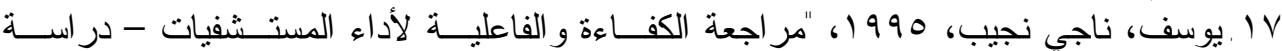

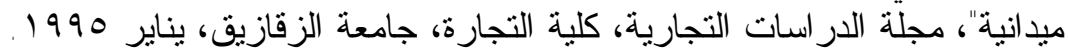

ثانياً - المر اجع باللغة الاجنبية

1. AICPA Committee on Management Services, Statement on Management Advisory Services No. (1), February 1969, As Edited in "CICPA" Professional standards", Vol. 1, As of June 1, 1981.

2. Antle, R. 1987, "Auditor's Independence", The Journal of Accounting Research, Vol. 22, No. 1, (Spring 1987).

3. Arthur, and Jr. Schulte, 1996, "Management Services", A challenge to Audit Independence", The Accounting Review.

4. Barnes, D.M., Bedard, G., Miller, B.D., Caine, B., Plamer, R., Gregory, J.P. and Wingate, A.K (1991), "Value-For-Money Evidence", A Research Study, The Canadian Institute of Chartered Accountants, Canada, 1991.

5. Braiotla, L., 1992, "A Local Practitioner's Guide to Internal Audit Service", The Certified Public Accountants, Journal Online, (May 1992).

6. Coats, J. F., 2001, "The Future As A Factor in Business Planning and Management", Futures Research Quarterly, Vol. 17, No. 3, 2001.

7. Connell, D.W. and Apostolou, B., 1992, "The Internal Auditor's Responsibility for Environmental Issues", Internal Auditing, (Spring 1992).

8. Fitzemeyer, J.R., 1976, "Should Internal Auditing be performed by A staff of Generalists of by A Specialized staff?", The Internal Auditior, (August 1976).

9. Forrest, J.S., 1999, "The Internal Audit and the Activity Based Management", The CPA Journal Online, (August 1999).

10. Goldman, D., 2000, "Leadership that Gets Results", Harvard Business Review, (March/April 2000), Vol. (78), No. (2).

11. Grinker, R.L., 1980, "The Auditor's Responsibility in Expressing An Opinion", The Journal of Accountancy, 1980.

12. Hines, A., 2002, "A Practitioner's View of the Future of Futures Studies", Futures, Vol. (34), No. (3-4).

13. Humphrey, et.al, 1992, "Providing Managerial and Consulting Services to Clients", The Institute of Chartered Accountants in the United Kingdom (England and Wiles), London: ICAEW, 1992. 
14. Hylton, D.P., 1964, "Are Consulting and Auditing Compitable A Contrary View", The Accounting Review, (July 1964).

15. Mclemore, L., 1997, "Expanding the Mission of Internal Audit", Controller Magazine, (July 1997).

16. Newell, G.E., Kneuse, J.G. and Newell, S.J., 1997, "Environmental Contamination", The National Public Accountant, (June 1992).

17. Rittenberg, L.E. (1997), "Auditor's Independence and Systems Design", Institute of Internal Auditors, USA, 1977.

18. Slaughter, R., 1999, "A New Framework for Environmental Scanning", Foresigher, Vol. (1), No. (5), (October 1999).

19. The Institute of Internal Auditors, 1998, "Standards for the Professional Practice of Internal Auditing", Altamonte Springs, Florida, USA, 1998, Standard No. (300), Scope of Work.

20. Voros, J., 2001, "Re-Framing Environmental Scanning: An Integrated Approach", Foresight, Vol. (3), No. (6), (December 2001). 